\title{
PAUL SRODECKI
}

Justus-Liebig-Universität Gießen / Ostravská univerzita v Ostravě

E-Mail: Paul.Srodecki@geschichte.uni-giessen.de

\section{"QUIA INTER VOS STABILITA CONCORDIA EST VALDE OPPORTUNA“ \\ ZU DEN VERMITTELNDEN KRÄFTEN IM \\ KONFLIKT ZWISCHEN DEM DEUTSCHEN ORDEN \\ UND DEM KÖNIGREICH POLEN IM FRÜHEN}

15. JAHRHUNDERT*

Das späte 14. Jahrhundert brachte einschneidende Veränderungen in der Mächtekonstellation des nordöstlichen Mitteleuropa mit sich. Mit dem Abschluss der Union von Krewo zwischen dem Königreich Polen und dem Großfürstentum Litauen 1385 wurde ein mächtiges, von der südukrainischen Steppe bis nach Großpolen reichendes Herrschaftskonglomerat geschaffen, das sich als konstituierend für die Geschichte dieses Raumes bis weit ins späte 18 . Jahrhundert erweisen sollte ${ }^{1}$. Weitreichen-

* Der vorliegende Artikel entstand im Rahmen der Untersuchungen des von der Historischen Fakultät der Universität Ostrava und des Ostravaer Zentrums zur Erforschung der Gesellschaft und Kultur des Mittelalters VIVARIUM getragenen Sonderforschungsbereichs „The Collective Identities in the Social Networks of Medieval Europe' (IRP)".

1 B. Nowak, Krewo - Lublin - Kraków 1385-1386. W kręgu twórców unii polskolitewskiej, in: Unia Lubelska 1569 roku w dziejach Polski i Europy, hg. v. A. A. Witusik, 
de Konsequenzen hatte die polnisch-litauische Union vor allem für den Deutschordensstaat in Preußen. Letzterer fand sich nach der Heirat des Gediminiden Jogaila mit Hedwig von Polen von einer mächtigen, wenn auch nicht immer zusammenhaltenden polnisch-litauischen Koalition in die Zange genommen. Die Beschlüsse von Krewo führten zu einer zusätzlichen Verschlechterung der per se schon angespannten Beziehungen zwischen dem Ordensstaat und seinen polnisch-litauischen Nachbarn. Die diplomatischen Spannungen des späten 14. und frühen 15. Jahrhunderts entluden sich in dem bewaffneten Konflikt der Jahre 1409-1411, den die Zeitgenossen wie auch später der polnische Historiograph Jan Długosz rückblickend als „magnus conflictus“2 bezeichneten und der in der vernichtenden Niederlage der Ordensritter gegen ein von ruthenischen und tatarischen Hilfstruppen unterstütztes

(2004), S. 7-12; H. Wisner, Spory o Krewo, „Zapiski Historyczne“, 69, 2-3 (2004), S. 169-179; J. Kiaupienè, 1385 m. rugpjūčio 14 d. Krèvos aktas, (2002); J. Tęgowski, Bezkrólewie po śmierci Ludwika Węgierskiego a geneza unii Polski z Litwą, in: Studia historyczne $z$ XIII-XV wieku. Wydanie jubileuszowe z okazji 75-lecia urodzin i 45-lecia pracy naukowej Profesora doktora Kazimierza Jasińskiego, hg. v. J. Śliwiński, (Studia i materiały WSP w Olsztynie 86, 1995), S. 87-110; M. Koczerska, Autentyczność dokumentu unii krewskiej 1385 roku, „Kwartalnik Historyczny“, 99, 1 (1992), S. 59-80; Dzieło Jadwigi i Jagiełty. W sześćsetlecie chrztu Litwy i jej związków z Polską. Antologia historyczno-literacka, hg. v. W. Biliński, (1989); L. Korczak, O akcie krewskim raz jeszcze (na marginesie rozprawy Jonasa Dainauskasa), „Studia Historyczne“, 34, 3 (1991), S. 473-479; W 600-lecie aktu krewskiego, hg. v. M. Biskup, „Zapiski Historyczne“, 51 (1986); H. Łowmiański, Akt krewski z 14 sierpnia 1385 roku, „Nurt“, 21, 8 (1985), S. 22-24; M. Hellmann, Die polnisch-litauische Union von 1385/1386. Betrachtungen zu ihrem 600jährigen Gedächtnis, „Jahrbücher für Geschichte Osteuropas N. F.“ (weiter: JGO), 34 (1986), S. 19-34; J. Bardach, Krewo i Lublin. Z problemów unii polsko-litewskiej, „Kwartalnik Historyczny“, 76, 3 (1969), S. 583-619.

2 So beispielsweise der polnische König Władysław II. Jagiełło im Jahre 1410 wie auch später Jan Długosz in seinen Annales seu cronicae incliti Regni Poloniae. Źródła do dziejów polskich, 1, hg. v. M. Grabowski, A. Przezdziecki, (1843), S. 159; Joannis Dlugossii Annales seu Cronicae incliti Regni Poloniae. Liber X et liber XI: 1406-1412, hg. v. C. Baczkowski (et al.), (1997), passim. 
polnisch-litauisches Heer bei Tannenberg sowie der anschließenden Belagerung Marienburgs seine militärischen Höhepunkte fand ${ }^{3}$.

Die dynastische Union zwischen Polen und Litauen verschlechterte jedoch nicht nur die außenpolitische Lage des Ordensstaates. Für die Ordensritter stellte der in Krewo vereinbarte Übertritt der Litauer zum Christentum auch den Beginn einer schweren Identitätskrise dar. Die raison dêtre schien dem Orden entzogen zu sein, war doch der im 13. Jahrhundert pro defensione Christianitatis gegründete Ordensstaat von nun an zumindest de iure von christlichen Nachbarn umgeben. Die Christianisierung Litauens bedeutete zudem ein Versiegen des Zuzugs westlicher, allem voran aus dem Heiligen Römischen Reich kommender Kreuzfahrer, die noch im 13. und 14. Jahrhundert den als cruciatae ausgerufenen Preußen- und Litauerreisen gerne in den Osten folgten. Die schwindende Unterstützung aus dem Westen zeigte sich für den Orden bereits in dem "Großen Krieg" 1409-1411; die allegorische Selbsttitulierung der Ordensritter als schilt der cristenheit verkam allmählich zu einer „leeren Propagandaformel“" .

3 Vgl. hierzu Tannenberg - Grunwald - Žalgiris 1410. Krieg und Frieden im späten Mittelalter, hg. v. W. Paravicini (et al.), (2012); Wojna Polski i Litwy z zakonem krzyżackim w latach 1409-1411, hg. v. S. Jóźwiak (u. a.), (2010); M. Biskup, Das Echo der Tannenbergschlacht und der Belagerung Marienburgs im deutschen Zweig des Deutschen Ordens im Sommer 1410, in: Beiträge zur Geschichte des Deutschen Ordens, 2, hg. v. U. Arnold, (Quellen und Studien zur Geschichte des Deutschen Ordens 49, Veröffentlichungen der Internationalen Historischen Kommission zur Erforschung des Deutschen Ordens 5, 1993), S. 116-123; K. Militzer, Auswirkungen der Schlacht bei Tannenberg auf den Deutschen Orden, in: Žalgirio laikų Lietuva ir jos kaimynai, hg. v. R. Čapaitè, A. Nikžentaitis, (Acta Historica Universitatis Klaipedensis 1, 1993), S. 94-112; S. M. Kuczyński, Wielka wojna z Zakonem Krzyżackim w latach 1409-1411, (1987); S. Ekdahl, Die Schlacht bei Tannenberg 1410. Quellenkritische Untersuchungen, 1: Einführung und Quellenlage, (Berliner Historische Studien 8, 1982).

${ }^{4}$ H. H. Hofmann, Der Staat des Deutschmeisters. Studien zu einer Geschichte des Deutschen Ordens im Heiligen Römischen Reich Deutscher Nation, (Studien zur bayerischen Verfassungs- und Sozialgeschichte 3, 1964), S. 86. Zum „schilt der cristenheit“Topos vgl. P. Srodecki, Schilt der Cristenheite i Scutum christianitatis - spory polskokrzyżackie a retoryka przedmurza/tarczy na początku XV wieku, in: Unia w Horodle na 
Der Konflikt zwischen Ordensstaat und Polen wurde dabei nicht nur militärisch, sondern auch diplomatisch ausgefochten. Beide Konfliktparteien betrieben im frühen 15. Jahrhundert eifrig Propaganda, um das Ausland von der Richtigkeit der eigenen Sache zu überzeugen. Der Orden warf beispielsweise Polen das Paktieren mit Heiden und Schismatikern wie die Schändung von Kirchen und Klöstern vor, Polen hingegen dem Orden das Töten von polnischen Christen und die gewaltsame Missionierung der Litauer ${ }^{5}$. Der Erste Thorner Frieden vom 1. Februar 1411 konnte die Auseinandersetzung nur für kurze Zeit beilegen ${ }^{6}$. Schon bald brachen neue, von der Nachwelt als „Hungerkrieg“ bezeichnete Kampfhandlungen aus, denen erneute bilaterale Verhandlungen zwischen dem Orden und Polen im kujawischen Grabie folgten. Als auch hier nennenswerte Ergebnisse ausblieben, wurde die Konfliktbewältigung zwischen beiden Streitparteien - wie bereits im Zweiten Ofener Schiedsspruch im selben Jahr beschlossen - auf das Konzil von Konstanz vertagt ${ }^{7}$.

Letzteres bot als diplomatisches Ereignis beiden Kontrahenten eine willkommene Bühne zur propagandistischen Stilisierung der eigenen Seite zum scutum, antemurale, propugnaculum etc. der Christenheit. Von Interesse ist hierbei allem voran die theologisch-juristische Beru-

tle stosunków polsko-litewskich. Od Krewa do Zaręczenia wzajemnego Obojga Narodów, hg. v. S. Górzyński, (2015), S. 147-163.

5 P. Srodecki, Antemurale Christianitatis. Zur Genese der Bollwerksrhetorik im östlichen Mitteleuropa an der Schwelle vom Mittelalter zur Frühen Neuzeit, (2015), S. 111ff.

6 S. Ekdahl, Der 1. Thorner Frieden (1411) im Spiegel der Söldnerfrage, „Ordines militares“, 18 (2013), S. 67-80; W. Sieradzan, Der Thorner Frieden von 1411 und die Prozesse zwischen dem Deutschen Orden und Polen als Beispiel der Bewältigung zwischenstaatlicher Konflikte im Spätmittelalter, in: Konfliktbewältigung und Friedensstiftung im Mittelalter, hg. v. R. Czaja, E. Mühle, A. Radzimiński, (2012), S. 135-150.

7 Z. H. Nowak, Protokół z rokowań polsko-krzyżackich w Grabiu i na kępie wiślanej pod Raciążkiem w roku 1414, „Ordines militares“, 2 (1984), S. 147-175; J. Goździelewski, Wojna polko-krzyżacka 1414 r., tzw. „wojna głodowa“, „Studia i materiały do historii wojskowości“, 16, 2 (1970), S. 19-61; M. Biskup, Wojny Polski z Zakonem Krzyżackim (1308-1521), (1993), S. 95-113; Hofmann, Staat, S. $80 f$. 
fung der jeweiligen Deputierten auf die Autorität des Konzils als supranationale Friedens- und Mediationsinstanz. Die Reden des Johannes Falkenberg, Peter von Wormditt, Ardicino della Porta de Novara oder Andrés Dias de Escobar auf der Seite des Deutschen Ordens wie auch des Paweł Włodkowic oder Andrzej Łaskarz auf der Seite Polens wurden in der Vergangenheit von der Geschichtsforschung in mehreren Abhandlungen thematisiert ${ }^{8}$. Im Folgenden soll jedoch wie im Titel

8 Im Folgenden nur eine kleine Auswahl an relevanter Forschungsliteratur: P. Srodecki, „Murus et antemurale pollens et propugnaculum tocius christianitatis“. Der Traktatenstreit zwischen dem Deutschen Orden und dem Königreich Polen auf dem Konstanzer Konzil, „Schweizerische Zeitschrift für Religions- und Kulturgeschichte“, 109 (2015), S. 47-65; R. Gogosz, Laws of Pagans and their Conversion in the Works of Pawet Włodkowic, in: Conversions. Looking for Ideological Change in the Early Middle Ages, hg. v. L. P. Supecki u. R. Simek, (2013), S. 137-152; J. Miethke, Die Polen auf dem Konstanzer Konzil. Der Konflikt um den Dominikaner Johannes Falkenberg, in: Das Konstanzer Konzil 1414-1418. Weltereignis des Mittelalters. Essays, hg. v. K.-H. Braun (et al.), (2013), S. 106-110; ders., Heiliger Krieg? Theoretische Kontroversen zwischen Deutschem Orden und dem Königreich Polen vor und auf dem Konstanzer Konzil, in: Heilige Kriege. Religiöse Begründungen militärischer Gewaltanwendung. Judentum, Christentum und Islam im Vergleich, hg. v. K. Schreiner, E. Müller-Luckner, (2008), S. 109-125; A. Szweda, Organizacja i technika dyplomacji polskiej $w$ stosunkach $z$ zakonem krzyżackim $w$ latach 1386-1454, (2009); C. J. Reid, Paulus Vladimiri, the Tractatus Opinio Hostiensis and the Rights of Infidels, in: Sacri canones servandi sunt. Ius canonicum et status ecclesiae saeculis XIII-XV, hg. v. P. Krafl, (Opera Instituti Historici Pragae. Series C, Miscellanea 19, 2008), S. 418-423; W. Czapliński, Pawet Włodkowic (Paulus Wladimiri) and the Polish international legal doctrine of the $15^{\text {th }}$ century, „Baltic Yearbook of International Law“, 7 (2007), S. 65-82; J. Krzyżaniakowa, Andrzej Łaskarz - „patron“ polskich koncyliarystów, in: Ludzie, kościót, wierzenia. Studia z dziejów kultury i społeczeństwa Europy Środkowej (średniowiecze - wczesna epoka nowożytna), hg. v. W. Iwańczak, (2001), S. 265-278; S. Kwiatkowski, Der Deutsche Orden im Streit um Polen-Litauen. Eine theologische Kontroverse über den Krieg und Frieden auf dem Konzil von Konstanz (1414-1418), (2000); L. Krzywiak, „Via concordiae “ czy „via iustitiae“ - jeszcze w sprawie „ostatniego słowa" Pawła Włodkowica o Zakonie krzyżackim, in: Cracovia - Polonia - Europa. Studia z dziejów średniowiecza ofiarowane Jerzemu Wyrozumskiemu w szęśćdziesiąta piata rocznice urodzin i czterdziestolecie pracy naukowej, hg. v. W. Bukowski (et al.), (1995), S. 323-327; F. Cheneval, Jean Falkenberg et Paul Vladimiri. Critiques de Dante, in: Société et église. Textes et discussions dans le Université d'Europe centrale pendant le moyen âge tardif. Actes du colloque international de Cracovie, 14-16 juin 1993, hg. v. Z. Włodek, (1993), S. 101-115; F. H. Russell, Paulus Vladimiri’s Attack on the Just War. 
bereits angedeutet verstärkt auf die Mediationsinstanzen, die „vermittelnden“ Akteure also, während dieser für das östliche Mitteleuropa in hohem Maße konstituierenden Auseinandersetzung des frühen 15. Jahrhunderts (vom sogenannten „Großen Krieg“ 1409-1411 bis zum Frieden von Melnosee 1422) eingegangen werden.

\section{SIGISMUND VON LUXEMBURG UND DER DEUTSCHE ORDEN}

Es war insbesondere Sigismund von Luxemburg, der sich in dem Konflikt zwischen dem Orden und Polen um eine - kraft seiner postulierten imperialen Autorität (anfangs als Reichsverweser des Heiligen Römischen Reiches, später als römisch-deutscher König) Schlichterrolle bemühte, letzten Endes vor allem aber als ein Anwalt der Ordensseite auftrat. Das Verhältnis des Luxemburgers zu Polen und Władysław II. Jagiełło war dabei mehrfach belastet. Durch seine erste Ehefrau, die Anjou-Königin Maria von Ungarn, stellte Sigismund zeit seines Lebens Ansprüche auf die polnische Krone, die er - ob ernsthaft

A Case Study in Legal Polemics, in: Authority and Power. Studies on Medieval Law and Government Presented to Walter Ullmann on his Seventieth Birthday, hg. v. B. Tierney, P. A. Linehan, (1980), S. 237-254; H. Boockmann, Johannes Falkenberg, der Deutsche Orden und die polnische Politik. Untersuchungen zur politischen Theorie des späteren Mittelalters, (1975); Z. Włodek, La Satire de Jean Falkenberg. Texte inédit avex introduction, (1973); J. Wiesiołowski, Prace i projekty Pawła Włodkowica. Konstancja, zima 1415 i 1416 roku, „Roczniki Historyczne“, 35 (1969), S. 93-123; K. A. Fink, Der Streit zwischen dem Deutschen Orden und Polen auf den Konzilien zu Konstanz und Basel, in: Reformata Reformanda, Festgabe für Hubert Jedin zum 17. Juni 1965, 1, hg. v. E. Iserloh, K. Repgen, (1965), S. 74-86; S. F. Bełch, Paulus Vladimiri and his Doctrines Concerning International Law and Politics, 2 Bde. (1965); L. Ehrlich, Rektor Paweł Włodkowic. Rzecznik obrony przeciw Krzyżakom, (Uniwersytet Jagielloński. Wydawnictwa jubileuszowe 6, 1963); H.-D. Kahl, Die völkerrechtliche Lösung der „Heidenfrage“ bei Paulus Vladimiri von Krakau (+1435) und ihre problemgeschichtliche Einordnung, „Zeitschrift für Ostforschung“ (weiter: ZfO), 7 (1958), S. 161-209; K. Springmann, Polen und der Deutsche Orden zur Zeit des Konstanzer Konzils, (1923). 
oder eher aus taktischen Gründen - mit der Titulierungsformel „Herre des Kunyghreichs zu Polan“ bzw. „dominus regni Poloniae“ in zahlreichen Urkunden zu untermauern suchte ${ }^{9}$. Im Gegensatz zu Jagiełło war der Luxemburger - durch seine Mutter, Elisabeth von Pommern - als Urenkel Kasimirs des Großen zudem ein Abkömmling der Piastendynastie. Eine Tatsache, die insbesondere nach dem Tod Hedwigs von Polen im Jahre 1399 Sigismunds Forderungen gegenüber Jagiełło mehr Gewicht verlieh ${ }^{10}$. Doch auch Sigismund musste umgekehrt gegen polnische Ansprüche auf den ungarischen Thron ankämpfen, brachte doch eine nicht unbedeutende Adelsopposition in Ungarn nach dem Unfalltod Marias von Anjou im Frühjahr 1395 Hedwig von Polen bzw. ihren Gemahl Władysław Jagiełło als legitime Nachfolger mit der Stephanskrone in Verbindung ${ }^{11}$.

Neben den dynastischen Spannungen zwischen beiden Herrschern, den polnisch-ungarischen Grenzstreitigkeiten in der Hohen Tatra, Ruthenien und Podolien sowie der von beiden Seiten immer wieder beanspruchten Suprematie über das Donaufürstentum Moldau barg vor allem das mehr als freundschaftliche Verhältnis des Luxemburgers zum Deutschen Orden hohes Konfliktpotential' ${ }^{12}$. Bereits Sigismunds

9 Codex diplomaticus Brandenburgensis, 4, hg. v. P. W. Gercken, (1771), Nr. 218, S. 411. Vgl. J. K. Hoensch, König/Kaiser Sigismund, der Deutsche Orden und PolenLitauen. Stationen einer problembeladenen Beziehung, „Zeitschrift für OstmitteleuropaForschung", 46, 1 (1997), S. 1-44, hier S. 3; W. Baum, Kaiser Sigismund. Hus, Konstanz und Türkenkriege, (1993), S. 24.

10 B. Paszkiewicz, Jak Zygmunt Luksemburski nie został królem Polski. Kilka uwag o domniemanym skarbie z Hrabušic, in: Lucemburkové. Mince, medaile, hg. v. D. Grossmannová, J. Hásková, J. T. Štefan, (Peníze v proměnách času 5, 2006), S. 23-34; C. Lübke, Das östliche Europa, (Die Deutsche und das europäische Mittelalter, 2004), S. 423; J.Skrzypek, Zygmunt Luksemburski i jego polityka wobec Polski w latach 1386-1399, „Sprawozdania Towarzystwa Naukowego we Lwowie“, 12, 3 (1932), S. 183-190, hier: S. 183.

11 Hedwig von Polen erweiterte nach Marias Tod ihre Titulatur um das Prädikat „Erbin des Königreichs Ungarn“. Vgl. Hoensch, König/Kaiser Sigismund, S. 8f.

12 Baum, Kaiser Sigismund, S. 29-31 u. 64-71; A. Mironowicz, Kościół prawosławny 
Großvater, König Johann von Böhmen, hatte den Ordensrittern sowohl finanzielle wie auch militärische Unterstützung im Konflikt mit dem polnischen König Władysław I. Łokietek zukommen lassen und sich an mehreren Feldzügen des Ordens gegen die Litauer beteiligt ${ }^{13}$. Auch Johanns Sohn, Kaiser Karl IV., hatte die Ordensritter fortwährend mit zahlreichen Privilegien ausgestattet und seine Unterstützung mit der Bedeutung des Ordensstaates für die Verteidigung des christlichen Glaubens und insbesondere des römisch-deutschen Reichs begründet ${ }^{14}$.

Das Argument der Glaubensverteidigung findet sich auch in zahlreichen Schreiben Sigismunds, der die Ordensritter anfangs in ihrem Konflikt gegen Polen und Litauen eifrig unterstützte. Immer wieder unterstrich der Luxemburger die Bedeutung der Ordensritter für die Christenheit wie auch das Reich, seien diese doch gleich einem „scutum Christi“ zur Verteidigung vor den Heiden an den Grenzen der Christenheit positioniert worden. Sollte sich der polnische König nicht mit einer rechtlichen Beilegung des Konflikts mit den Ordensrittern begnügen, so sei es, mahnte Sigismund im Juni 1410, seine Pflicht als „Vicarius des Heiligen Römischen Reiches“, dem Deutschen Orden, diesem „schilte wider dy ungelawbigen“, nicht nur diplomatisch und fi-

w państwie Piastów i Jagiellonów, (2003), S. 148; J. Matijov, Der polnisch-ungarische Streit um Galizien und Lodomerien (Ein Beitrag zur österreichischen Geschichte), (1886).

13 W. Iwańczak, Krucjaty Jana Luksemburskiego, in: Rycerstwo Europy ŚrodkowoWschodniej wobec idei krucjat, hg. v. W. Peltz, J. Dudek, (Historia 5, 2002), S. 113-121; ders., Jan Luksemburski a Polska, in: Polacy w Czechach, Czesi w Polsce X-XVIII wiek, hg. v. H. Gmiterka, W. Iwańczak, (2004), S. 13-30.

14 Codex Diplomaticus Prussicus, 3, hg. v. J. Voigt, (1848 = ND 1965), Nr. 91, S. 121; Die Urkunden des Deutsch-Ordens-Centralarchives zu Wien, 1, hg. v. E. G. v. Pettenegg, (1887), Nr. 1354, S. 355. Vgl. Hofmann, Staat, S. 77; B. Jähnig, Der Deutsche Orden und Karl IV., in: B. Jähnig, Vorträge und Forschungen zur Geschichte des Preußenlandes und des Deutschen Ordens im Mittelalter. Ausgewählte Beiträge zum 70. Geburtstag am 7. Oktober 2011, hg. v. H.-J. Kämpfert, B. Kämpfert, (Quellen und Darstellungen zur Geschichte Westpreußens 34, 2011), S. 16-66, hier $25 \mathrm{f}$. 
nanziell, sondern gegebenenfalls auch militärisch zur Seite zu stehen ${ }^{15}$. Sigismunds Drohungen Richtung Polen waren wohl mehr taktischer Natur als ernst gemeinte Kriegsgesten. Nach dem Tod Ruprechts von der Pfalz am 18. Mai desselben Jahres wie auch der hierdurch entstandenen Thronvakanz bildete das öffentliche Eintreten für den Deutschen Orden ein wirkungsvolles Mittel im anstehenden Wahlkampf um die römisch-deutsche Königskrone, hatten sich doch gerade die Kurfürsten in der Vergangenheit für die Sache der vornehmlich aus dem deutschsprachigen Raum rekrutierten Ordensritter eingesetzt ${ }^{16}$.

Als ein Indiz für diese Vermutung mag die Tatsache gelten, dass Sigismund - trotz der ungarischen Kriegserklärung an Polen vom 17. Juni 1410 - nur mit großer militärischer Zurückhaltung und Reserviertheit gegen Polen vorging. Der Luxemburger begnügte sich in der Folge mit der Entsendung einer kleineren Truppe unter dem siebenbürgischen Woiwoden Stibor an die ungarisch-polnische Grenze ${ }^{17}$. Im

15 Schreiben vom 16. Juni 1410, Lites ac res gestae inter Polonos Ordinemque Cruciferorum (weiter: Lites), 2, hg. v. I. Zakrzewski, Z. Celichowski, (1892), Add. Nr. 60, S. 450. Vgl. auch die lateinische Version vom 21. Juni 1410, Scriptores rerum Prussicarum. Die Geschichtsquellen der preussischen Vorzeit bis zum Untergange der Ordensherrschaft (weiter: SRP), 3, hg. v. T. Hirsch, M. Töppen, E. Strehlke, (1866 = ND 1965), S. 402: „Nunc autem predicti [die Deutschordensritter] nos tamquam vicarium sacri Romani imperii invocarunt, presertim ex quo pro parte sancte Romane ecclesie et sacri imperii in finibus christianitatis pro clipeo contra infideles sint positi et in sacri Romani imperii tuicione sint, quod nos ipsis assistentes suffragari vellemus, sicud hoc nobis ex officio incumbit, etiam secundum quod hoc ipsis tenemur faciendum. Unde, ex quo predicti taliter et in sacri imperii et nostri imperialis officii protectione esse dinoscuntur, ergo petimus vos, quod circa pronunciacionem prenominati nostri domini et fratris maneatis, ipsosque molestare ultra debitum desinatis, pronunciacioni juris et principaliter deo et toti christianitati nostreque protectioni in eo deferentes; sin autem, quod ipsi de nostris precibus tante justitie patrocinium habere non possent, extunc nos oportet volumusque ipsis auxiliari contra vos et infideles ac contra omnes, cum quibus vos prefatos et christianitatem nitimini debilitare“.

16 O. Israel, Das Verhältnis des Hochmeisters des Deutschen Ordens zum Reich im 15. Jahrhundert, (Wissenschaftliche Beiträge zur Geschichte und Landeskunde OstMitteleuropas 4, 1952), S. 9.

17 F. Sikora, Kilka uwag o konflikcie węgiersko-polskim w roku 1410, „Rocznik 
völligen Kontrast zu den halbherzig durchgeführten Kriegshandlungen stand hingegen Sigismunds diplomatisches Wirken. Nur kurze Zeit nach dem Debakel des Ordens bei Tannenberg im Juli 1410 sandte der ungarische König einen Appell an die gesamte abendländische Christenheit und rief alle Gläubige zu den Waffen, um den Ordensrittern zu Hilfe zu eilen und den Tod des Hochmeisters Ulrich von Jungingen zu rächen. Bemerkenswerterweise stilisierte er hierbei den Kampf des Ordens gegen Polen und Litauen in bester Kreuzzugsmanier zu einem Konflikt des christlichen Kulturkreises gegen eine Welt des Unglaubens. Das Faktum des Krieges gegen das christliche Polen umging der Luxemburger schlicht und einfach und erwähnte es mit keinem Wort. Laut Sigismund war vielmehr die Niederlage bei Tannenberg ausschließlich das Ergebnis eines aussichtlosen Kampfes der Ordensritter und ihrer Verbündeten gegen eine zahlenmäßig erdrückende Koalition wütender Heiden und Schismatiker - der Litauer, Žemaiten, Ruthenen und Tataren. Diese Übermacht hätte nicht nur dem Ordensland Preußen, sondern auch den angrenzenden christlichen Ländern großen Schaden zugefügt, sei doch seit dem Sieg der Heiden der Orden, der als "clipeus defensionis“ das christliche Abendland im Preußenland und dem Baltikum beschütze, schwer angeschlagen ${ }^{18}$.

Naukowo-Dydaktyczny WSP w Krakowie. Prace Historyczne“, 12 (1987), S. 105-118; Hoensch, König/Kaiser Sigismund, S. 12; S. A. Sroka, Ścibor ze Ściborzyc. Rys biograficzny, in: Polska i jej sąsiedzi w późnym średniowieczu. Profesorowi Jerzemu Wyrozumskiemu - uczniowie, hg. v. K. Ożóg, S. Szczur, (2000), S. 139-158, hier 153-155. Vgl. D. Dvořáková, Polacy na dworze węgierskim za panowania Zygmunta Luksemburskiego. Ścibor ze Ściborzyc i jego krewni, in: Genealogia. Rola związków rodzinnych i rodowych $w$ życiu publicznym $w$ Polsce średniowiecznej na tle porównawczym, hg. v. A. Radzimiński, J. Wroniszewski, (1996), S. 171-180.

18 SRP 3, S. 403: „Compaciencie spiritu inducimur vestris fraternitatibus, excellenciis, magnificenciis, benivolenciis et virtutibus clarissimis significare rem detestabilem proch dolor! nuper perpetratam, ex intimis cordis nostri dolentes, quomodo pridem permittente altissimo Christi populus fidelis, felicis memorie frater Ulricus de Jungingen, magister generalis ordinis Theotonicorum, dominus terre Prussie, et potiores ordinis ejusdem preceptores tunc presentes cum multis principibus, ducibus, comitibus, illustribus et aliis viris strennuis et famosis bellatoribus Christi inclitis 
Auch nach der Beilegung des Konflikts zwischen dem Deutschen Orden und seinen polnisch-litauischen Kontrahenten im sogenannten Ersten Thorner Frieden vom 1. Februar 1411 setzte sich Sigismund auf internationaler Bühne für die Ordensritter ein. Seinen Bruder Wenzel etwa forderte der inzwischen zum römisch-deutschen König gekrönte Sigismund auf, gegen die Anwerbung böhmischer, mährischer oder schlesischer Söldner durch das Königreich Polen einzuschreiten. Zudem sollte Wenzel, dessen Verhältnis zum Ordensritterorden durchaus belastet war ${ }^{19}$, zur Rückgabe der 1233 gegründeten und wirtschaftlich überaus lukrativen Ballei Böhmen-Mähren bewegt werden. Letztere wurde 1410 zur Finanzierung von Söldnerkontingenten für den bevorstehenden Konflikt mit Polen und Litauen an die böhmische Krone verpfändet, konnte aber ob der nach dem Thorner Frieden und den hiermit verbundenen Reparationszahlungen mehr als prekären finanziellen Lage vom Orden nicht wieder herausgelöst werden ${ }^{20}$. Mit der

sinistraque fortuna volente casualiter in bello campestri et paganorum rabidorum Littuanorum, Samartanorum, Rutenorum et Tartarorum et aliorum crucis Christi totiusque christiane religionis notoriorum emulorum et persecutorum cohortibus multiplicatis et catervis devicti in ore gladii ceciderunt et interfecti fuerunt pro Christi nomine et defensione terre Prussie pugnantes, quorum reliquiis clipeum defensionis et tutele populi christiani et terre Prussie adhuc tenentibus constanter nisi in manu forti et brachio excelso festine succurratur et mature, ex cohortibus paganorum eorundem et persecutorum crucis Christi, qui continuo confluunt catervatim et in obsidionem posuerunt quasi totam terram dominorum Theotonicorum predictorum et signanter castrum principale Margenburg [Marienburg] vocatum, in quo thesaurus eorum habetur et cor terre existit, prout ex nunciorum relatu nostrorum et eorum fidelium continuo instruimur et pro subsidio invocamur, intollerabili et irrecuperabili ruine et periculo personarum atque rerum adeo submittentur, quod regna et terre, dominia et principatus christianorum circumjacentia et circumjacentes gaudere minime possunt de salute".

19 Vgl. H. Vetter, Die Beziehungen Wenzels zum Deutschen Orden von 1384-1411, (1912).

20 J. Sarnowsky, Die Wirtschaftsführung des Deutschen Ordens in Preußen (1382-1454), (Veröffentlichungen aus den Archiven Preußischer Kulturbesitz 34, 1993), S. 321f. Zur Deutschordens-Ballei Böhmen-Mähren und ihrer wirtschaftlichen Bedeutung vgl. M. Čapský, Die wirtschaftliche Entwicklung der Ballei Böhmen des Deutschen 
Gesandtschaft an den böhmischen Hof in Prag beauftragte Sigismund den Burggrafen Friedrich von Nürnberg. In den Anweisungen an den Hohenzollern bildete wiederum das Schild-Motiv den argumentativen Kern der Forderungen an Wenzel:

Wann nu derselbe Orden zu dem Romischen Riche, dem wir nu von göttlicher schickunge vurgesetzit sin, gehörit und ein fester schilt der christenheit an dem Ort vil Jar gewesen ist, und ob Got wil furbaß sin sol. Darumb geburte uns y von des Riches und Recht und auch der ganzen Christenheit wegin zu tun [...], daz der vorgenante Orden icht me viruneret werde ${ }^{21}$.

In dem Schreiben an Friedrich wird die Zuspitzung der negativen Darstellung Polens im Konflikt mit dem Deutschen Orden deutlich. Sigismund beschuldigte das Königreich Polen nun noch dezidierter eines Verrats an den Grundprinzipien der abendländischen Christenheit. Unter der Führung ihres verschlagenen Königs Jagiełło seien die Polen vom rechten Weg des Glaubens abgekommen und hätten

[...] sich mit Lithauern und Tattern und andern ungläubigen unßers Herren Jesu Christi und sins Glaubens lesteren beholffen und die

Ordens im Spätmittelalter, in: Die geistlichen Ritterorden in Mitteleuropa. Mittelalter, hg. v. K. Borchardt, J. Libor, (Edice Země a kultura ve střední Evropě 20, 2011), S. 215-232; ders., Zbraně a zbroj v inventář́ch komend českomoravské bailie rádu německých rytírư, „Acta historica et museologica Universitatis Silesianae Opaviensis“, 7 (2007), S. 59-66; ders., Fiskální vazby českomoravské bailie a velmistrovské komory řádu německých rytî́r̊ „,Sborník prací Filozofické fakulty brněnské univerzity C 46“, 48 (1999), S. 67-77; A. Mentzel-Reuters, Arma spiritualia. Bibliotheken, Bücher und Bildung im Deutschen Orden, (Beiträge zum Buch- und Bibliothekswesen 47, 2003), S. 340-343; J. Libor, Zkáza českomoravské bailie řádu německých rytî́r̊u, „Časopis Matice moravské“, 117 (1998), S. 383-391; H. G. Böhm, Die Deutschordens-Ballei Böhmen und Mähren, (Schriftenreihe der Historischen Deutschordens-Compagnie zu Mergentheim 12, 1993); J. Hemmerle, Die Deutschordens-Ballei Böhmen in ihren Rechnungsbüchern 1382-1411, (Quellen und Studien zur Geschichte des Deutschen Ordens 22, 1967).

21 J. Aschbach, Geschichte Kaiser Sigismund 's, 1 (1838), Beilage Nr. 6, S. 427. 
manig Cristenplut virgoßen, unschuldige kinder Wibsbilder ermortet, Frawen und Jungfrawen ersmehet hinweg gefüret, das heilige Sacramente gevirert, kirchen, kloster und gotshußer als jemerlichen verergert $^{22}$.

Diametral entgegen gesetzt bewertete der Luxemburger hingegen freilich den Deutschen Orden. Als verdienter „Schild der Christenheit“ dürfe dieser vom christlichen Abendland nicht im Stich gelassen werden, sei es doch „nicht allein dem Orden, sunder aller Cristenheit und zuvor an allen konigen, fürsten und Ritterschaft die darumb furgesetzit und gewirdiget sin“, aufgetragen worden, „daz sie unßern Glauben, daz Cristenfulk beschirmen sullen ${ }^{23}$.“

Ähnliche Argumentationen finden sich in weiteren Schreiben Sigismunds, so beispielsweise an die deutschen Reichsstädte wie auch an einzelne geistliche und weltliche Reichsfürsten. An Nikolaus von Reibnitz etwa appellierte der König im Dezember 1411, dieser möge von seiner durch ausgebliebene Soldzahlungen seitens der Ordensritter aufgenommenen Fehde gegen den Orden ablassen und sich - dem ritterlichen Ethos folgend - wieder dem Kampf gegen die Feinde der Christenheit - sprich: des Ordens - anschließen: Da „derselb orden der ganzen cristenheit vester schilt wider die ungleubigen und aller ritterschaft fruntlicher und nuczlicher ufenthalt vil jare gewest ist, und [...] fürbaz sein sol [...]“, müssten „alle fürsten edeln ritterschaft und cristenblute billicher mitleiden mit im haben und im zu hilf komen. Dorumb begeren wir von euren treuen mit ganzem ernst und flisse, daz ir die vorgenante entsagung abetut ${ }^{24}$." An Sigismunds Aufruf an Nikolaus von Reibnitz wird die Flexibilität und polyvalente Funkti-

22 Ebd., S. 428.

23 Ebd.

24 Schreiben vom 15. Dezember 1411, Geheimes Staatsarchiv Preußischer Kulturbesitz Berlin (weiter: GStA PK), OBA Nr. 1605. Abgedruckt bei Israel, Verhältnis, Anhang Nr. 8, S. 87. Vgl. Das Soldbuch des Deutschen Ordens 1410/1411, hg. v. S. Ekdahl, (Veröffentlichungen aus den Archiven Preußischer Kulturbesitz 23, 2, 2010). 
onalität des Bollwerksmotivs deutlich, das als rhetorisches Stilmittel der Diplomatie gegenüber einem breitgefächerten Publikum in unterschiedlichen Konstellationen immer wieder angewandt werden konnte. Anders als in den oben zitierten Schreiben stand hierbei nicht mehr die ganze Christenheit oder die Reichsfürsten als geschichtsbedingte Anwälte des Ordens im Vordergrund, sondern vielmehr der ritterliche Habitus und die damit verbundenen Pflichten gegenüber dem Orden als dem „Heim“ der abendländischen (insbesondere aber der deutschen) Ritterschaft und dem glaubensverteidigenden Vorposten der Christenheit ${ }^{25}$. Diese Argumentationsweise hatte bei Sigismund durchaus Methode, hatte er doch bereits nach der Niederschlagung einer ungarischen Adelsopposition im Zuge der verlorenen Schlacht von Nikopolis 1396 an den ritterlichen Geist einflussreicher Adelshäuser wie etwa derer von Semsey de Semse appelliert und die Unterstützung seines Königtums - als Parallele zum von Nikolaus von Reibnitz postulierten Eintreten für den Deutschen Orden - offen mit der Glaubensverteidigung verknüpft ${ }^{26}$.

25 Diese Verbundenheit zum deutschen Adel spiegelte sich nicht zuletzt in der in der Frühen Neuzeit aufgekommenen Wendung „des armen deutschen Adels Spital“ für den Deutschen Orden wider. Vgl. hierzu M. Armgart, Vom Spital der Armen zum Spital des Adels. Der Deutsche Orden im Reich und seine Niederlassung in Einsiedel bei Kaiserslautern, „Arbeitsgemeinschaft für Geschichtliche Landeskunde am Oberrhein e. V.“, 382 (1999), S. 1-27; V. Press, „Des deutschen Adels Spital“. Der Deutsche Orden zwischen Kaiser und Reich, in: Der Deutsche Orden in Tirol. Die Ballei an der Etsch und im Gebirge, hg. v. H. Noflatscher, (Quellen und Studien zur Geschichte des Deutschen Ordens 43, 1991), S. 1-42. Zum ritterlichen Habitus und der einhergehenden Verpflichtung zur Glaubensverteidigung siehe. J. B. Gillingham, Crusading Warfare, Chivalry, and the Enslavement of Women and Children, in: The Medieval Way of War. Studies in Medieval Military History in Honor of Bernhard S. Bachrach, hg. v. G. I. Halfond, (2015), S. 133-152; B. Gebert, Poetik der Tugend. Zur Semantik und Anthropologie des Habitus in höfischer Epik, in: Text und Normativität im deutschen Mittelalter. XX. Anglo-German Colloquium, hg. v. E. Brüggen (et al.), (2012), S. 143-168; W. Haug, Das „ritterliche Tugensystem“. Norm oder Herausforderung?, in: Symposium „Das Mittelalter in der Gegenwart", 25.-27.09.1995, hg. v. I. Hoppner, (Veröffentlichungen des Japanisch-Deutschen Zentrums Berlin. Reihe 1, Deutsch 30, 1996), S. 56-70.

26 Srodecki, Antemurale Christianitatis, S. 100. Zum Kreuzzug von Nikopolis 
Sigismunds Werben für eine aktive Kriegsunterstützung des Ordens bei den Reichsständen ist insofern bemerkenswert, verhandelte er doch zeitgleich im Hintergrund mit Polen und Litauen über einen Friedensvertrag. Jagiełło drohte dem Luxemburger nach dem Wegfall des Deutschen Ordens als Konfliktpartei mit einer aus Polen, Litauen, den Donaufürstentümer Moldau und Walachei, dem Herzogtum Innerösterreich unter Ernst dem Eisernen sowie der Republik Venedig bestehenden und gegen Ungarn gerichteten Allianz ${ }^{27}$. Sigismund lenkte ein und so mündeten die Verhandlungen mit Polen noch im März 1412 in einem Friedensvertrag mit Jagiełło, dem etwa einen Monat später auch Vytautas beitrat ${ }^{28}$. Der Luxemburger verpflichtete sich unter anderem, ein Schiedsgericht über die Streitigkeiten zwischen der polnisch-litauischen Allianz und dem Deutschen Orden zu halten, dem schließlich der sogenannte Erste Schiedsspruch von Ofen Ende August 1412 folgte und im Wesentlichen die Vereinbarungen des Friedens von Thorn bestätigte ${ }^{29}$. Seiner Autorität schadete das Nachgeben im Streit mit Polen-Litauen vorerst jedenfalls nicht, trat doch der mittlerweile zum römisch-deutschen König gekrönte Luxemburger in der Folge nach außen als wohlwollender Mediator auf ${ }^{30}$.

1396 vgl. ders., Contre les ennemis de la foy de Dieu. Der Kreuzzug von Nikopolis und das abendländische Türkenbild um 1400, in: Das Bild des Feindes. Konstruktion von Antagonismen und Kulturtransfer im Zeitalter der Türkenkriege, hg. v. E. Leuschner u. T. Wünsch, (2013), S. 33-49.

27 Hoensch, König/Kaiser Sigismund, S. 13-15.

28 Ebd., S. 15.

29 H. Boockmann, Ofen, Schiedsspruch von (1412), in: Lexikon des Mittelalters (weiter: LMA), 6 (1993), Sp. 1365-1366.

30 Vgl. N. Z. Hubert, Międzynardowe procesy polubowne jako narzędzie polityki Zygmunta Luksemburskiego w pótnocnej i środkowowschodniej Europie (1412-1424), (1981). 


\section{DiE REICHSFÜRSTEN ALS ANWÄLTE DES DEUTSCHEN ORDENS}

Die europaweite Propagandatätigkeit des Deutschen Ordens wie auch Sigismunds von Luxemburg diplomatische Unterstützung zeigten aber recht bald ihre Wirkung ${ }^{31}$. Gegenpapst Johannes (XXIII.) etwa ehrte im Januar 1415 auf dem Konzil von Konstanz öffentlich den Ordensstaat als „scutum fidei“ und die Ordensritter als „defensores christianitatis“, die einst „allegabant terras et dominia Lichwanie videlicet paganicas et Russie scismaticas ${ }^{32}$. "Insbesondere im Heiligen Römischen Reich als dem Ursprungsland der Ordensritter hatte der Orden als „geistlichritterliche Institution" viele Sympathisanten in dem reichsöffentlichen Umfeld $^{33}$. Es mag also kaum verwundern, dass gerade im Reich das Bild des Deutschen Ordens als christliches Bollwerk, das von den Polen im Verbund mit heidnischen Hilfstruppen bestürmt werde und dringend Hilfe brauche, sich großer Beliebtheit erfreute. Die starke Bindung zwischen Reich und Orden zeigten sich auch in der weit verbreiteten Empörung über das Umschwenken Sigismunds von Luxemburg und seinen Ofener Schiedsspruch, der als eine Unterstützung von Glaubensfeinden sowie ein Affront gegenüber den Ordensrittern und somit auch gegenüber dem Reich angesehen wurde. Zeugnis hiervon liefern die zahlreichen Schreiben der Reichsfürsten an Sigismund aus jener Zeit. Kurz nach dem Friedensschluss zwischen Sigismund und Władysław Jagiełło und noch vor dem Ofener Schiedsspruch ermahnte beispielsweise der Wittelsbacher Ludwig der Gebartete, der spätere Herzog von

31 Vgl. K. Polejowski, The Teutonic Order's Propaganda in France during the Wars against Poland and Lithuania (Fifteenth Century), in: Die geistlichen Ritterorden in Mitteleuropa. Mittelalter, hg. v. K. Borchardt, J. Libor, (Edice Země a kultura ve střední Evropě 20, 2011), S. 233-244.

32 Codex Epistolaris Saeculi Decimi Quinti (weiter: CESDQ), 2, hg. v. A. Sokołowski, J. Szujski, A. Lewicki, (Monumenta medii aevi historica res gesta Poloniae illustrantia 12, 1891), Nr. 57, S. 67.

33 J. Seiler, Der Deutsche Orden in Frankfurt. Gestalt und Funktion einer geistlichritterlichen Institution in ihrem reichsöffentlichen Umfeld, (Quellen und Studien zur Geschichte des Deutschen Ordens 61, 2003). 
Bayern-Ingolstadt, im Namen der Reichsfürsten den römischen König, dieser möge dem Orden, dem Schild der Christenheit, gegen den König von Polen und seinen Vetter Vytautas, die sich mit Russen, Tataren und anderen Ungläubigen verbunden hätten, beistehen:

Gnediger Here, sint nü der egenante Duczsche Orden vorher eyn vester Schilt der Cristenheyt gewest ist, unde sulde der von den Ungelowbegen gedrucket unde unbillich vortilgit werden, do Got mitsampt üweren Gnaden vor seyn, das daz der gancen Cristenheyt eyn grosser Schade würde unde dovon. Denn der Küning von Polen unde Herczok Wittold haben sich mit den Rüssen, Tattern unde andern ungeloubigen Luten vorbunden $[\ldots]$ unde meynen, in unde seynen Orden unde das Kristentumb mit dem Krige czu vorlegen unde czu vortilgen ${ }^{34}$.

In Ludwigs Appell werden noch einmal die an die römisch-deutsche Königswürde verknüpften und seit der späten Stauferzeit gewachsenen Verpflichtungen gegenüber dem Orden deutlich. Sigismund habe mit dem von den Reichsfürsten ihm anvertrauten Königsamt auch die Aufgabe übernommen, den Ordensrittern „in pflichtiger Beschirmunge“ stets ein Beschützer zu sein, damit „nicht allein dem Orden, sunder der gancen Cristenheyt gros Gnade unde Furdrung" geschehe ${ }^{35}$. Ein ähnliches Schreiben sandte der Wittelsbacher etwa einen Monat später an den Gegenpapst Johannes (XXIII.). Letzterer dürfe unter keinen Umständen solch renommierte und im Glaubenskampf für Kirche wie Kaiserreich verdiente „pugiles et defensores“ wie die Ordensritter im Stich lassen ${ }^{36}$.

\section{Lites 2, Nr. 8, S. 41.}

35 Ebd.

36 Ebd., Nr. 14, S. 48: „In casu vero sy eidem sic exstirparentur, quod absit, eo tunc sancta Romana Ecclesia, sacrum Romanorum imperium sub orbe universo tantos non habent pugiles et defensores, qui eis in tribulacionibus suis tantum subsidium defendendi exhiberent, et pagani una cum infidelibus in gentem magnam crescunt: exurgat ergo sanctitas vestra celeriter, ne deterius fiat, ipsosque, ut prefertur, pocius protegere 
Neben Ludwig dem Gebarteten waren es aber vor allem die geistlichen Reichsfürsten, die nach dem Ersten Thorner Frieden aktiv für die Ordenssache eintraten. Erzbischof Johann II. von Mainz etwa wandte sich noch im Frühjahr 1412 mit einer ähnlichen Forderung an Sigismund, der sich seiner Verpflichtungen als weltliches „Heubt der Cristenheit" bewusst werden müsse. Hierzu zählten dem Erzbischof zufolge allem voran die Verteidigung des in schwere Bedrängnis geratenen Deutschen Ordens, der seit über zwei Jahrhunderten „ein Offhalt aller Ritterschaft und ein merglich Leit dez heilgen Richez" gewesen $\mathrm{sei}^{37}$.

Insbesondere „daz Lant zü Prüszen“ dürfe nicht untergehen, sei es doch ein wichtiger „Schilt der Cristenheit gein dem vorgeschriben Konig von Polanne und Herczoge Witaüw“"38. Johanns Amtskollege, der Kölner Erzbischof Friedrich III. von Saarwerden, ging hierbei noch einen Schritt weiter und erhöhte in einem wenige Wochen später verfassten Brief an Johannes (XXIII.) rhetorisch die Bedeutung des Ordensstaates, als er von der Unversehrtheit des letzteren nicht nur das Wohl des römisch-deutschen Reiches, sondern vielmehr der ganzen abendländischen Christenheit abhängig machte. Johannes (XXIII.) müsse dem „beklagenswerten Unrecht", das dem Orden, diesem „erfolgreichen Schild“ der römischen Kirche und des Kaiserreichs,

et defendere intendat, pro quo vobis sancteque Romane [Ecclesie cum] omnibus meis adherentibus fideliter subiugabor".

37 Deutsche Reichstagsakten. Ältere Reihe (1376-1485) (weiter: RTA ÄR), 8, hg. v. J. Weizsäcker, (1883, ND 1956), Nr. 6, S. 12: „timens itaque, beatissime pater, exempli non modicam perniciem et alia inconveniencia secutura sanctitatem vestram instancia qua possum supplico: quatinus mendacis opposicionibus contradiccionibus aut impungnationibus non velitis aures apostolicas aliquatenus inclinare; set, nedum dictum ordinem in suis dominiis et territoriis occasione eorum de quibus compromissum per partem adversam jam diu tribulatum et jam fere in exterminio constitutum in detrimentum cristiane religionis (cujus insigne propugnaculum et antemurale validum esse dinoscitur) ne contingat indebite amplius molestari, silencium pocius tam frivolis ut videtur ambagibus imponere studeatis".

38 Ebd., Nr. 9, S. 41f. 
„von dem polnischen König, dem Herzog Vytautas und einer Vielzahl Ungläubiger" angetan worden sei, ein Ende bereiten ${ }^{39}$.

Ein weiteres Beispiel für die Unterstützung, die die Großen des Reiches dem Orden in seinem Konflikt mit Polen und Litauen zukommen ließen, bietet ein Schreiben vom 8. Januar 1419. So ermahnten gleich fünf Kurfürsten, die Erzbischöfe von Mainz, Köln und Trier sowie Ludwig, der Pfalzgraf bei Rhein, und Friedrich I., Markgraf von Brandenburg-Ansbach, Sigismund von Luxemburg, er möge wie bereits vor einigen Jahren zwischen den erneut in Bedrängnis geratenen Ordensrittern und dem immer mächtiger werdenden Königreich Polen vermitteln. Die permanenten Kriege an der nordöstlichen christlichen Peripherie seien „gar schedelich und sorglich [...]“ und zwar „nit allein Dutschen landen sunder auch der gemeinen cristenheit und dem heiligen Romschen riche". Schließlich sei doch ein Kampf zwischen zwei christlichen Parteien ein für alle anderen Gläubigen verderblicher Zustand. Vielmehr werde der Orden als ein langjähriger „ufhalt und

39 Ebd., Nr. 15, S. 48f.: „Vestram sanctitatem cupio non latere, quin honorabilis frater Ordinis Theutonicorum dominus Heinricus de Plauwin, in Pruszie partibus eiusdem Ordinis supremus magister et rector, honorandum fratrem Georgium Eglingen, preceptorem domus supradicti Ordinis in Thoran, de omnibus apud se gestis instruendum me plenarie transmisit. Qui ante frater recitatus lamentabilem iniuriam, angustiam, vexacionem et tribulacionem Ordinis antedicti, per regem Polonie, ducem Witoldum ac infidilium multitudinem ipsis assistentem procuratas proponendo declaravit, quod vestra sanctitate nuper eadem puncta cum aliis sacrosancti Romani causis michi scribente, eandem opinor non latere. Sed quia professores Ordinis expressati et provincia Prutenorum sancte matris Ecclesie et imperii Romani ex illo mundi climate scutum efficax fuerant hucusque, et cum certe a vestra sanctitate tamquam Christianorum capite suam exspectant et affectant a tanto periculo, miseria et oppressione liberacionem et proteccionem, quemadmodum vestra graciosa sanctitas una cum aliis Christianitatis defectibilitatis [sic!], ut in vestre invincibilis sanctitatis litteris intellexi, ad cor revocavit: sic ego vestrum servitorum humilimus fratribus cum supradictis vestram graciositatem imploro indefesse, quatenus vestra sanctitatis Ordinem antefatum, gloriose Virgini et suis servulis fortiter militantem, a tam voracium luporum, scilicet regis Polonie, ducis Witoldi ac ipsis in hac parte adiacentibus [sic!], dignatur [sic!] principaliter propter Dei laudem, Christianitatis necessitatem et sacrosancti Romani Ecclesie honorem, dentibus asistere contuendum“. 
schirm [...] der cristenheit" nach dem Auftauchen der Osmanen auf dem europäischen Kontinent längst an anderen Grenzen des Abendlandes gebraucht. So könnten die von einem Konflikt mit Polen befreiten Ordensritter an der unteren Donau eingesetzt werden und so „zu hulfe und der ganzen cristenheit und nemelich [...] Ungern zu droste widder die unglaubigen" kommen ${ }^{40}$. Ähnliche Forderungen schloss auch ein weiteres, von denselben Kurfürsten - diesmal allerdings ohne den Markgrafen von Brandenburg-Ansbach - verfasstes Schreiben vom 27. August 1419 ein: Sigismund als „vogt und beschermer“ der Ordensritter sei durch die römisch-deutsche Königswürde geradezu an die Aufgabe gebunden, mit allen Mitteln den Orden, „der [...] an sinem ort der ganzen cristenheit vester nuczelicher und lobelicher fridschilt und alles adels getruwer ufhalt vil jar gewest und noch ist und ob Got will noch lange zit sin sol“, zu entlasten ${ }^{41}$.

Die kurfürstlichen Appelle fielen in eine Zeit, als Gerüchte laut wurden, Sigismund habe die Seiten gewechselt und wolle sich mit Władysław Jagiełło gegen den Deutschen Orden wenden. Die Beschuldigungen waren nicht ganz unbegründet, hatte sich doch der römischdeutsche König in den Jahren zuvor - bei gleichzeitiger Entfremdung zu den finanziell wie militärisch angeschlagenen Ordensrittern - kontinuierlich dem Königreich Polen angenähert, von dem er sich nach dem sogenannten ersten Prager Fenstersturz Ende Juli 1419 Unterstützung in seinem Kampf gegen die böhmischen Hussiten erhoffte ${ }^{42}$. Der Kurswechsel in den bilateralen Beziehungen zu Polen wird insbesondere in den Bollwerkszuschreibungen jener Zeit deutlich, mit denen Sigismund seinen einstigen Widersachern schmeichelte. Wurde letzterer, wie oben aufgeführt, während des „Großen Krieges" nicht müde, die Stellung des Deutschordensstaates als „Schild der Christenheit“ im Reich wie im übrigen Abendland zu propagieren, so pries er diesmal die Polen samt

\footnotetext{
40 RTA ÄR 7, Nr. 253, S. 374 f.

41 Ebd., Nr. 271, S. 396-397.

42 Vgl. Israel, Verhältnis, S. 15-27.
} 
ihres Königs als tugendhafte Glaubenskämpfer, die die „lorica“ und den „scutum fidei“" gegen die „barbarras exterasque [...] naciones" an den östlichen Grenzen der Christenheit hochhielten ${ }^{43}$. Entsprechend groß fiel die Empörung der Kurfürsten über die Annäherung Sigismunds und Jagiełłos aus. So warnten sie den Luxemburger vor einem irreparablen Ansehensverlust, der gar sein erst vor wenigen Jahren erworbenes römisch-deutsches Königtum stark beschädigen könnte:

Ir solt in [den Deutschen Orden] doch nach dem und ir dem reiche fürgesetzt und der heiligen kirche vogt seid, billicher bei gleich und recht hanthaben und im zulegen und beholfen sein etc. [...] Werdet ir dem vorgenanten von Polan wider den orden helfen, euch werden so merclich und gross rüfe red und wort darumbe auf stehen und komen, die euch vast swere einfelle und scheden bringen mochten ${ }^{44}$.

\section{PÄPSTLiCHE MediationsVERsuCHE UNTER MARTIN V.}

Es verwundert somit nicht, dass die Kurfürsten sich in den frühen 1420er Jahren verstärkt dem Heiligen Stuhl zuwandten, um für den Orden entlastende Unterstützung zu erlangen. Otto von Ziegenhain etwa schrieb Anfang März 1421 an Papst Martin V., dieser solle der polnischen Diplomatie, die den Orden auf internationaler Bühne zu desavouieren suchte, kein Wort glauben. Wie in den Jahrhunderten zuvor, so stelle auch heute noch der Ordensstaat ein ,insigne propugnaculum

43 So z. B. in einem in Januar 1418 an den polnischen König verfassten Brief, CESDQ 2, Nr. 88, S. 108: „Verum quia divinarum scripturarum testante eloquio sicuti Moyses sub legis vetuste tipo ex fide grandis factus est, quanto magis nos, qui per fidem et graciam filii dei existimus, victores terrenarum potestatum esse poterimus, dum lorica fidei circumdati, scutum fidei assumpmentes, vinculo caritatis cathenati, quascunque barbarras exterasque comprimimus naciones".

44 Israel, Verhältnis, Anhang Nr. 21, S. 96. 
et antemurale validum " dar, dessen Fortbestand mit dem Heil der ganzen Christenheit verknüpft sei ${ }^{45}$. Anders als seine Vorgänger stellte sich Martin V. nicht akritisch und ohne jeden Widerspruch auf die Seite des Ordens. Vielmehr bemühte sich der Papst um eine parteilose Schlichtung des Konfliktes. Im Herbst 1421 beauftragte Martin den päpstlichen Legaten Antonio Zeno mit der Mediation in dem nicht enden wollenden Konflikt zwischen der polnisch-litauischen Union und dem Deutschen Orden. In Martins Schreiben fällt die Einschätzung beider Konfliktparteien sehr salomonisch aus; auf die positive Hervorhebung der einen zuungunsten der anderen Partei wird weitgehend verzichtet. An Sigismund von Luxemburg schrieb der Pontifex im November 1421 beispielsweise, dass sowohl Polen als auch der Deutsche Orden von immenser Bedeutung für die Glaubensverteidigung wie -ausbreitung seien. Beide bildeten unverzichtbare „Bollwerke“ an den Grenzen der von Kriegen, Häresien und allgemeiner Zwietracht geplagten christianitas. Seiner Rolle als geistliches Oberhaupt nachkommend wolle der Papst Polen und dem Orden den Justizweg aufzwingen und somit dem Streit ein Ende setzen, „ut partes ab offensionibus abstinerent“. Auch Sigismund als weltlicher Souverän der Christenheit, als , pugil et defensor fidei et reipublice christiane", müsse seinen Pflichten Genüge

45 Schreiben vom 1. März 1421, RTA ÄR 8, Nr. 6, S. 12: „timens itaque, beatissime pater, exempli non modicam perniciem et alia inconveniencia secutura sanctitatem vestram instancia qua possum supplico: quatinus mendacis opposicionibus contradiccionibus aut impungnationibus non velitis aures apostolicas aliquatenus inclinare; set, nedum dictum ordinem in suis dominiis et territoriis occasione eorum de quibus compromissum per partem adversam jam diu tribulatum et jam fere in exterminio constitutum in detrimentum cristiane religionis (cujus insigne propugnaculum et antemurale validum esse dinoscitur) ne contingat indebite amplius molestari, silencium pocius tam frivolis ut videtur ambagibus imponere studeatis“. Zu Otto von Ziegenhain vgl. M. Persch, Otto von Ziegenhain, in: Biographisch-Bibliographisches Kirchenlexikon, 6 (1993), S. 1375-1377; R. Holbach, „Disz ist dy ansprache dy wir dun wydder unssern heren... ". Bemerkungen zur Regierungszeit des Erzbischofs Otto von Ziegenhain (1418-1430), „Kurtrierisches Jahrbuch“, 23 (1983), S. 17-35. 
tun und offenkundiger als zuvor den Friedensprozess zwischen beiden Parteien vorantreiben ${ }^{46}$.

Martin V. beteuerte auch gegenüber dem polnischen König seine Entschlossenheit, den Konflikt nachhaltig zu entschärfen. Viel wichtiger war dem Papst die Niederschlagung der hussitischen Häretiker. Die Niederlagen der katholischen Heere bei Kuttenberg und Deutschbrod wie auch das damit zusammenhängende Scheitern des Dritten Hussitenkreuzzugs Anfang 1422 bestärkten Martin in der Auffassung, eine Rückeroberung Böhmens für die katholische Kirche sei nur mit vereinten Kräften der mitteleuropäischen Mächte, vor allem aber mit der Unterstützung Polens und des Deutschen Ordens möglich. So ermahnte der Papst Ende März desselben Jahres Jagiełło erneut mit Nachdruck, dieser solle seinen langjährigen Konflikt mit den Ordensrittern endlich und endgültig beilegen. Nur wenn zwischen den beiden „festesten Bollwerken der Christen“ Eintracht herrsche, könne der „schrecklichen Häresie, die das Königreich Böhmen entweiht", dauerhaft beigekommen werden ${ }^{47}$.

46 Schreiben vom 13. November, CESDQ 2, Nr. 100, S. 128f.: „Cum igitur inter alia bella, quibus christianitatis inflammata noscatur, dudum videmus bellum grave atque pestiferum in ipsis propugnaculis christianorum excitatum, videlicet inter carissimum in Christo filium nostrum Vladislaum Polonie regem illustrem et dilectum filium nobilem virum Alexandrum Lituanie ducem pro parte una et dilectos filios magistrum et fratres ordinis b. Marie de domo Theutonicorum pro parte altera, multa tentavimus multa fecimus, ut ipsos ad pacem et concordiam duceremus, nec pie preces nec charitative hortaciones nostre defuerunt et si non possemus aliter iuxta desiderium nostrum discordiam eam sedare, ne peiora detrimenta sequerentur, parti utrique promisimus controversiam totam auditis partibus per viam iusticie terminare, procurantes interea, ut prorogarentur inducie, ut partes ab offensionibus abstinerent“.

47 Ebd., Nr. 104, S. 140f.: „Cum nulla res hodie tantum sollicitet et afficiat mentem nostram, quantum horribilis illa et adversa deo heresis, que regnum Bohemie maculavit, ut regni ipsius excidium et tocius christianitatis infamiam eamque maculam ex oculis fidelium tolli et aboleri et sequaces exterminari hereticos vel penitentes reduci ad gremium ecclesie super omnia cupiamus. [...] Et quoniam ad hereticos confundendos et debilitandos et reprimendos eorum furores, qui de dissencione fidelium letantur et sperant, tuam pacem et concordiam cum Prutenis plurimum profuturam esse putamus, interea prefato legato commisimus, ut cum factus propinquior regno tuo 


\section{DER FRIEDEN VON MELNOSEE 1422}

Die päpstlichen wie reichsfürstlichen Interventionsversuche waren letzten Endes jedoch erfolgslos. Bereits im Sommer 1422 mündeten die wieder aufgebrochenen Spannungen zwischen der polnisch-litauischen Union und dem Deutschen Orden nach einer knapp achtjährigen Waffenpause in einem neuen Krieg. Die in der Vergangenheit vermeintlich uneingeschränkte Solidarität der Reichsfürsten gegenüber den Ordensrittern hatte diesmal signifikante Risse bekommen. Anders als in den vorherigen militärischen Auseinandersetzungen mit dem Deutschen Orden konnte sich Polen mit Friedrich von Hohenzollern, dem Markgrafen von Brandenburg, dessen Sohn Friedrich die Ehe mit Jagiełłos Tochter Hedwig in Aussicht gestellt worden war, derweilen die Unterstützung eines einflussreichen Potentaten aus dem Reich sichern. Die oben aufgezählten, treu zum Orden haltenden Reichsfürsten begnügten sich hingegen mit diplomatischen Bekundungen, ein militärisches Eintreten blieb jedoch aus. Als es im Juli 1422 zu ersten Kriegshandlungen der überlegenen polnisch-litauischen Truppen kam, erklärte sich der politisch isolierte Orden im Frühherbst zu Friedensverhandlungen bereit, an deren Ende der Frieden vom Melnosee vom 27. September 1422 stand. Ein Novum hierbei war der gewachsene

[sit], studeat explorare, quid tunc super hac composicionis materia factum erit per dilectum filium magistrum Antonium Zeno decretorum doctorem referendarium et nuncium nostrum, quem pridem hac de causa destinavimus ad serenitatem tuam et ad dilectos filios nostros nobilem virum Alexandrum Lituanie ducem et magistrum et fratres hospitalis sancte Marie de domo Theutonicorum, et si expedire cognoverit, apud te et apud alios, quorum consensus est necessarius, se interponere et nunciis ac litteris solicitare non desinat, eciam si opus esset se ad tuam presenciam conferendo, ut pax ilia vestra sequetur, que et propter ipsius magnam honestatem et communem militarium gencium utilitatem ab apostolico legato, cuius proprium est pacem fidelium procurare, merito est procuranda, et quia inter vos, qui estis firmissima propugnacula christianorum, stabilita concordia est valde opportuna [...], hoc est ad confusionem et exterminium vel salutarem reduccionem hereticorum, qui cum aspexerint christianos fideles vicinos esse concordes, sustinere se posse in sua pertinacia desperabunt". 
Stellenwert der preußischen Stände. Verglichen mit früheren Verhandlungen zwischen Polen und dem Deutschen Orden traten sie nun als ein zusätzlicher bedeutender Akteur auf die diplomatische Bühne, der mehr Mitspracherecht in den innen- wie auch außenpolitischen Entscheidungen des Ordensstaates verlangte. Die an einer Kontinuität der lukrativen Handelskontakte zu Polen interessierten preußischen Stände waren sodann auch die treibende Kraft hinter der friedlichen Beendigung des Konfliktes und verpflichteten sich als Garanten der Beschlüsse vom Melnosee zum offenen Widerstand bei Vertragsbruch seitens des Ordens ${ }^{48}$.

Für die Ordensritter bedeutete der Friedensschluss aber eine weitere, nicht nur mit Gebietsverlusten verbundene Degradierung auf internationaler Bühne: So mussten sie neben der Abtretung des kujawischen Nessau samt des Gebiets am Oberlauf der Netze auch ihren endgültigen Verzicht auf Samogitien erklären. Władysław Jagiełło wiederum gab seine Ansprüche auf Pommerellen, das Kulmer und das Michelauer Land auf. Vor allem aber die signifikante Einflussnahme der preußischen Stände auf den Ausgang der Friedensverhandlungen in Melnosee warfen ihre Schatten auf zukünftige Entwicklungen innerhalb des Ordensstaates, die - einhergehend mit der Gründung des Preußischen Bundes 1440 - sich später in dem sogenannten Dreizehnjährigen

48 Die Staatsverträge des Deutschen Ordens in Preußen im 15. Jahrhundert, 1 , hg. v. E. Weise, (1939), Nr. 152-154, S. 150-164. Zu den Friedensverhandlungen und dem Frieden vom Melnosee allgemein siehe Dokumenty strony polsko-litewskiej pokoju mełneńskiego z 1422 roku, hg. v. P. Pokora, P. Nowak, (2004); K. Neitmann, Zur Revindikationspolitik des Deutschen Ordens nach Tannenberg. Die Auseinandersetzung zwischen d. Deutschen Orden und Polen-Litauen um die Ratifizierung des Friedensvertrages vom Melno-See 1422/1423, „JGO“, 31,1 (1983), S. 50-80; C. A. Lückerath, Melnosee, Friede von (1422), in: LMA, 6 (1993), Sp. 502; H. Chłopocka, Uwagi o zeznaniach wyższego duchowieństwa na procesie polsko-krzyżackim w latach 1422-1423, in: Docendo discimus. Studia historyczne ofiarowane Profersorowi Zbigniewowi Wielgoszowi $w$ siedemdziesiąta rocznice urodzin, hg. v. K. Kaczmarek, J. Nikodem, (Publikacje Instytutu Historii UAM 32, 2000), S. 317-333; E. Weise, Entwicklungsstufen der Verfassungsgeschichte des Ordensstaats Preußen im 15. Jahrhundert, „ZfO“, 7 (1958), S. 1-17, hier S. 4; Hofmann, Staat, S. $83 \mathrm{f}$. 
Krieg (1454-1466) entluden und in der Spaltung des Preußenlandes in ein der Krone Polen unmittelbar unterstelltes „Königliches Preußen“ samt Danzig und Marienburg sowie ein Restordensland Preußen mit Königsberg als dem neuen Hauptort unter polnischer Suzeränität mündeten. So gilt der Frieden vom Melnosee als ein wichtiger Meilenstein in der Geschichte des Ordensstaates in Preußen beim Übergang zum frühneuzeitlichen Territorialstaat ${ }^{49}$.

Zugleich vertieften die in Melnosee getroffenen Beschlüsse die Entfremdung des Ordenslandes Preußen zu den außerpreußischen Balleien, insbesondere denen im römisch-deutschen Reich. Der bislang bei Kaiser und Reich für den Hochmeister vermittelnde Deutschmeister Eberhard von Seinsheim verweigerte anfangs die Zustimmung zu

49 Vgl. B. E. Bockelmann, Die Lösung der preußischen Stände vom Deutschen Orden, in: Stadt und Land in der Geschichte des Ostseeraums. Wilhelm Koppe zum 65. Geburtstag überreicht von Freunden und Schülern, hg. v. K. Friedland, (1973), S. 121-126; K. Neitmann, Die ostpreußischen Stände und die Außenpolitik des Deutschen Ordens vom I. Thorner Frieden bis zum Abfall des Preußischen Bundes (1411-1454), in: Ordensherrschaft, Stände und Stadtpolitik. Zur Entwicklung des Preußenlandes im 14. und 15. Jahrhundert, hg. U. Arnold, (Schriftenreihe Nordost-Archiv 25, 1985), S. 27-71; Z. H. Nowak, Bemerkungen zur frühen Geschichte der Stände in Preußen, in: Die Anfänge der ständischen Vertretungen in Preußen und seinen Nachbarländern, hg. v. H. Boockmann, E. Müller-Luckner, (Schriften des Historischen Kollegs. Kolloquien 16, 1992), S. 52-54; R. Czaja, Der Handel des Deutschen Ordens und der preußischen Städte. Wirtschaft zwischen Zusammenarbeit und Rivalität, in: Ritterorden und Region. Politische, soziale und wirtschaftliche Verbindungen im Mittelalter, hg. v. Z. H. Nowak, (Ordines militares. Colloquia Torunensia Historica 8, 1995), S. 111-123; ders., Das Verhältnis der führenden Schichten der preußischen Großstädte zur Landesherrschaft in vergleichender Sicht im 14. und 15. Jahrhundert, in: Der Deutsche Orden in der Zeit der Kalmarer Union 1397-1521, hg. v. Z. H. Nowak, R. Czaja, (Ordines militares. Colloquia Torunensia Historica 10, 1999), S. 75-89; S. Salmonowicz, Königliches Preußen und polnisch-litauischer Staat (1466-1772), in: Reiche und Territorien in Ostmitteleuropa. Historische Beziehungen und politische Herrschaftslegitimation, hg. v. D. Willoweit, H. Lemberg, (Völker, Staaten und Kulturen in Ostmitteleuropa 2, 2006), S. 81-91; J. Małłek, Königliches Preußen, Ordensstaat und Herzogtum Preußen im 15. und 16. Jahrhundert. Entfremdung oder wirtschaftliche und politische Annäherung, „Blätter für deutsche Landesgeschichte“, 115 (1979), S. 1-14; M. Biskup, Das Königliche und das Herzogliche Preußen von der Mitte des 15. Jahrhunderts bis 1772, „Zeitschrift für historische Forschung“, 22 (1995), S. 49-70. 
dem Friedensvertrag von Melnosee und zeigte dadurch auch seinen Unwillen, die ausstehenden Forderungen gegenüber den angeworbenen Söldnerverbänden und den Reichsständen mit den Einkünften der Reichsbesitzungen des Ordens zu begleichen. Dass Seinsheim im Mai 1423 letzten Endes den Vereinbarungen von Melnosee doch zustimmte, war auch der Intervention Sigismunds von Luxemburg zu verdanken, der in Zeiten der Hussitenkriege wie oben erwähnt gemeinsam mit Papst Martin V. auf einen Frieden zwischen Polen und dem Deutschen Orden drängte ${ }^{50}$. Der Deutschmeister hegte aber noch Monate danach offen Unmut über die in seinen Augen schändlichen Bestimmungen von Melnosee, wie aus dem Inhalt eines am 22. Juli 1423 an den Hochmeister Paul von Rusdorf verfassten Schreibens deutlich wird. Seinsheim zufolge sei seine Enttäuschung exemplarisch für die in breiten Teilen der Reichsöffentlichkeit negative Meinung zu Melnosee gewesen. Als Beweis hierfür nannte der Deutschmeister die Empörung der auf dem Reichstag in Frankfurt versammelten Fürsten und Städte, die der Ordensführung Verweichlichung und Unfähigkeit vorgeworfen und die Schuld an dem langsamen Untergang „, des Schirmes und Schildes des christlichen Glaubens" zugewiesen hätten. Der Orden habe zugelassen, dass die in der Vergangenheit unter großen Opfern eroberten und errichteten Burgen und Schlösser leichtfertig dem Feind übergeben wurden, obwohl der römische König Sigismund Hilfe aus dem Reich versprochen hätte ${ }^{51}$.

50 Hofmann, Staat, S. 84.

51 RTA $\ddot{A} R$ 8, Nr. 254, S. 298: „Daruf auch den obgenanten unsern herren den fursten uwer briefe geantwort und soliche unsers ordens sache, so das glimpflichst gescheen mochte, furbracht wurden. Aber sie haben es alzü groblich und swerlich ufgenommen, und gefellet in gar nicht das sich unser orden als gar weichlich und liderlich sinen feinden widersetzet und also lichtlich und geringlich ubergeben hat slosse lande und lute, die vor ziten von iren altfordern fursten herren rittern und knechten als gar swerlich mit unmeßlicher vergiessunge cristenlichs blüts gebüwet gewonnen und uberkommen sin dem cristenlichen glauben zu eim sunderlichen schirme und schilde an dem orte, nemelich nach dem und der obgenant unser herre Romischer kung unserm orden solichen trost und hulfe zugesagt hette und auch keinen friden mit unsern widersachen 
Am Frieden von Melnosee lässt sich aber auch hervorragend die wechselhafte Rolle Sigismunds von Luxemburg innerhalb des Konflikts zwischen dem Deutschen Orden und dem Königreich Polen bzw. dem Großfürstentum Litauen im frühen 15. Jahrhundert erkennen. Sein undurchsichtiges Taktieren blieb eine der Konstanten in dieser diplomatischen Auseinandersetzung. Der Luxemburger wusste durch seine pragmatischen Frontwechsel zwischen Polen und Orden wie auch die Schaukelpolitik in den Beziehungen zu den größtenteils hinter den Ordensrittern stehenden Reichsfürsten geschickt die komplexen Verhältnisse im Beziehungsgeflecht Ostmitteleuropas für sich zu nutzen ${ }^{52}$. Nur einige Jahre nach Melnosee waren die Karten wiederum neu gemischt und Sigismund befand sich erneut auf Seiten des Ordens. Durch die Annäherung an Litauen und der geplanten - aber letztendlich nicht verwirklichten - Erhebung Vytautas zum litauischen König brachte der römisch-deutsche König gar die polnisch-litauische Union mächtig ins Schwanken ${ }^{53}$. Das von Jan Długosz geprägte durchwegs negative Bild Sigismunds in der polnischen Historiographie späterer Jahrhunderte konnte also dieser ambivalenten und durchaus sehr interessanten Person, die sehr viele Eigenschaften eines flexibel, fast schon real-politisch handelnden neuzeitlichen Herrschers erkennen ließ, nicht ganz gerecht werden ${ }^{54}$.

anghen wollte, es were dann unser orden genzlich mit in vereinet als obgeschriben stet“. Vgl. J. Sarnowsky, Der Deutsche Orden, (Beck'sche Reihe 2428, 2007), S. 62.

52 W. Iwańczak, Czy Jan Luksemburski był wrogiem Polski?, „Mówią Wieki“, 40,4-5 (1997), S. 17-21.

53 Srodecki, Antemurale, S. $128 \mathrm{ff}$.

54 Vgl. J. Nikodem, Wróg Królestwa Polskiego. Zygmunt Luksemburski w opinii Jana Długosza, in: Cor hominis. Wielkie namiętności w dziejach, źródłach i studiach nad przeszłością, hg. v. S. Rosik, P. Wiszewski, (Acta Universitatis Wratislaviensis. Historia 176, 2007), S. 183-199. 


\section{"QUIA INTER VOS STABILITA CONCORDIA EST VALDE OPPORTUNA“}

O SIŁACH POŚREDNICZĄCYCH W KONFLIKCIE MIĘDZY ZAKONEM KRZYŻACKIM A KRÓLESTWEM POLSKIM NA POCZĄTKU XV WIEKU

(STRESZCZENIE)

Artykuł dotyczy konfliktu między Zakonem Krzyżackim a Królestwem Polskim na początku XV wieku. Skupiono się w nim w mniejszym stopniu na fakcie wyniesienia tego konfliktu przed sobór w Konstancji i następnie powoływaniu się przez deputowanych podczas prowadzonych dyskusji na autorytet soboru. W większym stopniu zostały ukazane wpływy dyplomatyczne „sił trzecich“, jak Stolicy Apostolskiej, króla i książąt Świętego Cesarstwa Rzymskiego. Ramy czasowe określają ogólnie tak zwana „wielka wojna“ w latach 1409-1411 oraz pokój mełneński w roku 1422.

Tłumaczenie Renata

Skowrońska

\section{"QUIA INTER VOS STABILITA CONCORDIA EST VALDE OPPORTUNA“ \\ ZU DEN VERMITTELNDEN KRÄFTEN IM KONFLIKT ZWISCHEN \\ DEM DEUTSCHEN ORDEN UND DEM KÖNIGREICH POLEN \\ IM FRÜHEN 15. JAHRHUNDERT}

(ZUSAMMENFASSUNG)

Der Beitrag widmet sich mit der Auseinandersetzung zwischen dem Deutschen Orden und dem Königreich Polen im frühen 15. Jahrhundert. Im Fokus stehen hierbei weniger die Austragung des Konflikts auf dem Konstanzer Konzil und die Berufung der Deputierten in der Diskussion auf die Autorität des Konzils. Vielmehr werden diplomatische Einflüsse ausübender „Drittakteure“ beleuchtet, wie etwa der Heilige Stuhl, der König und die Fürsten des Heiligen Römischen Reiches. Den groben zeitlichen Orientierungsrahmen bilden hier der sogenannte „Große Krieg“ 1409-1411 und der Frieden von Melnosee 1422. 


\title{
"QUIA INTER VOS STABILITA CONCORDIA EST VALDE OPPORTUNA“
}

\author{
ABOUT THE INTERMEDIARY POWERS IN THE CONFLICT \\ BETWEEN THE TEUTONIC ORDER AND THE POLISH KINGDOM \\ AT THE BEGINNING OF THE $15^{\text {TH }}$ CENTURY
}

The article addresses the conflict between the Teutonic Order and the Polish Kingdom at the beginning of the $15^{\text {th }}$ century. The author to some extent focused on the fact of the conflict being presented at the Council of Constance and the fact that deputies referred to the authority of the council during discussions. To a greater extent the author demonstrated the diplomatic influence of the "third parties" such as the Holy See, the king and the princes of the Holy Roman Empire. The time framework constitutes the so called "Great War" in the years 1409-1411 and the peace treaty of Melno of 1422.

Translated by

Agnieszka Chabros

\section{Słowa kluczowe / Schlagworte / Keywords}

- Królestwo Polskie; Zakon Krzyżacki; koncyliaryzm; późnośredniowieczna dyplomacja

- Königreich Polen; Deutscher Orden; Konziliarismus; spätmittelalterliche Diplomatie

- Kingdom of Poland; Teutonic Order; conciliarism; late medieval diplomacy

\section{BIBLIOGRAFIA / BIBLIOGRAFIE / BIBLIOGRAPHY}

\section{ŹRÓDŁA ARCHIWALNE / ARCHIVALISCHE QUELLEN / ARCHIVAL SOURCES}

Geheimes Staatsarchiv Preußischer Kulturbesitz Berlin, OBA, Nr. 1605.

\section{ŹRÓDŁA DRUKOWANE / GEDRUCKTE QUELLEN / PRINTED SOURCES}

Annales seu cronicae incliti Regni Poloniae. Zrzódła do dziejów polskich, hg. v. M. Grabowski, A. Przezdziecki,1 (1843). 
Codex diplomaticus Brandenburgensis, 4, hg. v. P. W. Gercken, (1771).

Codex Diplomaticus Prussicus, 3, hg. v. J. Voigt, (1848 = ND 1965).

Codex Epistolaris Saeculi Decimi Quinti, 2, hg. v. A. Sokołowski, J. Szujski, A.Lewicki, (Monumenta medii aevi historica res gesta Poloniae illustrantia 12, 1891).

Das Soldbuch des Deutschen Ordens 1410/1411, hg. v. S. Ekdahl, (Veröffentlichungen aus den Archiven Preußischer Kulturbesitz 23, 2, 2010).

Deutsche Reichstagsakten. Ältere Reihe (1376-1485), 8, hg. v. J. Weizsäcker, (1883, ND 1956).

Die Staatsverträge des Deutschen Ordens in Preußen im 15. Jahrhundert, 1, hg. v. E. Weise, (1939).

Die Urkunden des Deutsch-Ordens-Centralarchives zu Wien, 1, hg. v. E. G.v. Pettenegg, (1887).

Dokumenty strony polsko-litewskiej pokoju mełneńskiego z 1422 roku, hg. v. P. Pokora, P. Nowak, (2004).

Joannis Dlugossii Annales seu Cronicae incliti Regni Poloniae. Liber X et liber XI: 1406-1412, hg. v. C. Baczkowski (et al.), (1997).

Lites ac res gestae inter Polonos Ordinemque Cruciferorum, 2, hg. v. I. Zakrzewski, Z. Celichowski, (1892).

Scriptores rerum Prussicarum. Die Geschichtsquellen der preussischen Vorzeit bis zum Untergange der Ordensherrschaft, 3, hg. v. T. Hirsch, M. Töppen, E. Strehlke, (1866 = ND 1965).

\section{LITERATURA / LITERATUR / LITERATURE}

Armgart M., Vom Spital der Armen zum Spital des Adels. Der Deutsche Orden im Reich und seine Niederlassung in Einsiedel bei Kaiserslautern,„Arbeitsgemeinschaft für Geschichtliche Landeskunde am Oberrhein e. V.“, 382 (1999), S. 1-27.

Aschbach J., Geschichte Kaiser Sigismund 's, 1 (1838).

Bardach J., Krewo i Lublin. Z problemów unii polsko-litewskiej, „Kwartalnik Historyczny“, 76, 3 (1969), S. 583-619.

Baum W., Kaiser Sigismund. Hus, Konstanz und Türkenkriege, (1993).

Bełch S. F., Paulus Vladimiri and his Doctrines Concerning International Law and Politics, 1-2 (1965).

Biskup M., Das Echo der Tannenbergschlacht und der Belagerung Marienburgs im deutschen Zweig des Deutschen Ordens im Sommer 1410, in: Beiträge zur Geschichte des Deutschen Ordens, 2, hg. v. U. Arnold, (Quellen und Studien zur Geschichte des Deutschen Ordens 49, Veröffentlichungen der Internationalen Historischen Kommission zur Erforschung des Deutschen Ordens 5, 1993), S. 116-123. 
Biskup M., Das Königliche und das Herzogliche Preußen von der Mitte des 15. Jahrhunderts bis 1772, „Zeitschrift für historische Forschung“, 22 (1995), S. 49-70.

Biskup M., Wojny Polski z Zakonem Krzyżackim (1308-1521), (1993).

Bockelmann B. E., Die Lösung der preußischen Stände vom Deutschen Orden, in: Stadt und Land in der Geschichte des Ostseeraums. Wilhelm Koppe zum 65. Geburtstag überreicht von Freunden und Schülern, hg. v. K. Friedland, (1973), S. 121-126.

Böhm H. G., Die Deutschordens-Ballei Böhmen und Mähren, (Schriftenreihe der Historischen Deutschordens-Compagnie zu Mergentheim 12, 1993).

Boockmann H., Johannes Falkenberg, der Deutsche Orden und die polnische Politik. Untersuchungen zur politischen Theorie des späteren Mittelalters, (1975).

Boockmann H., Ofen, Schiedsspruch von (1412), in: Lexikon des Mittelalters, 6 (1993), Sp. 1365-1366.

Čapský M., Die wirtschaftliche Entwicklung der Ballei Böhmen des Deutschen Ordens im Spätmittelalter, in: Die geistlichen Ritterorden in Mitteleuropa. Mittelalter, hg. v. K. Borchardt, J. Libor, (Edice Země a kultura ve střední Evropě 20, 2011), S. 215-232.

Čapský M., Fiskální vazby českomoravské bailie a velmistrovské komory řádu německých rytî́ưo ,,Sborník prací Filozofické fakulty brněnské univerzity C 46“, 48 (1999), S. 67-77.

Čapský M.,Zbraně a zbroj v inventárích komend českomoravské bailie rádu nèmeckých rytî́ů , „Acta historica et museologica Universitatis Silesianae Opaviensis“, 7 (2007), S. 59-66.

Cheneval F., Jean Falkenberg et Paul Vladimiri. Critiques de Dante, in: Société et église. Textes et discussions dans le Université d'Europe centrale pendant le moyen âge tardif. Actes du colloque international de Cracovie, 14-16 juin 1993, hg. v. Z. Włodek, (1993), S. 101-115.

Chłopocka H., Uwagi o zeznaniach wyższego duchowieństwa na procesie polskokrzyżackim w latach 1422-1423, in: Docendo discimus. Studia historyczne ofiarowane Profersorowi Zbigniewowi Wielgoszowi w siedemdziesiata rocznice urodzin, hg. v. K. Kaczmarek, J. Nikodem, (Publikacje Instytutu Historii UAM 32, 2000), S. 317-333.

Czaja R., Das Verhältnis der führenden Schichten der preußischen Großstädte zur Landesherrschaft in vergleichender Sicht im 14. und 15. Jahrhundert, in: Der Deutsche Orden in der Zeit der Kalmarer Union 1397-1521, hg. v. Z. H. Nowak, R. Czaja, (Ordines militares. Colloquia Torunensia Historica 10, 1999), S. 75-89.

Czaja R., Der Handel des Deutschen Ordens und der preußischen Städte. Wirtschaft zwischen Zusammenarbeit und Rivalität, in: Ritterorden und Region. Politische, 
soziale und wirtschaftliche Verbindungen im Mittelalter, hg. v. Z. H. Nowak, (Ordines militares. Colloquia Torunensia Historica 8, 1995), S. 111-123.

Czapliński W., Pawet Włodkowic (Paulus Wladimiri) and the Polish international legal doctrine of the $15^{\text {th }}$ century, „Baltic Yearbook of International Law“, 7 (2007), S. 65-82.

Dvořáková D., Polacy na dworze wegierskim za panowania Zygmunta Luksemburskiego. Ścibor ze Ściborzyc i jego krewni, in: Genealogia. Rola związków rodzinnych i rodowych $w$ życiu publicznym $w$ Polsce średniowiecznej na tle porównawczym, hg. v. A. Radzimiński, J. Wroniszewski, (1996), S. 171-180.

Dzieło Jadwigi i Jagiełty. W sześćsetlecie chrztu Litwy i jej związków z Polską. Antologia historyczno-literacka, hg.v. W. Biliński, (1989).

Ekdahl S., Der 1. Thorner Frieden (1411) im Spiegel der Söldnerfrage, „Ordines militares", 18 (2013), S. 67-80.

Ekdahl S., Die Schlacht bei Tannenberg 1410. Quellenkritische Untersuchungen, 1: Einführung und Quellenlage (Berliner Historische Studien 8, 1982).

Fink K. A., Der Streit zwischen dem Deutschen Orden und Polen auf den Konzilien zu Konstanz und Basel, in: Reformata Reformanda, Festgabe für Hubert Jedin zum 17. Juni 1965, 1, hg. v. E. Iserloh u. K. Repgen, (1965), S. 74-86.

Gebert B., Poetik der Tugend. Zur Semantik und Anthropologie des Habitus in höfischer Epik, in: Text und Normativität im deutschen Mittelalter. XX. Anglo-German Colloquium, hg. v. E. Brüggen (et al.), (2012), S. 143-168.

Gillingham J. B., Crusading Warfare, Chivalry, and the Enslavement of Women and Children, in: The Medieval Way of War. Studies in Medieval Military History in Honor of Bernhard S. Bachrach, hg. v. G. I. Halfond, (2015), S. 133-152.

Gogosz R., Laws of Pagans and their Conversion in the Works of Pawet Włodkowic, in: Conversions. Looking for Ideological Change in the Early Middle Ages, hg. v. L. P. Supecki u. R. Simek, (2013), S. 137-152.

Goździelewski J., Wojna polko-krzyżacka 1414 r, tzw. „wojna głodowa“, „Studia i materiały do historii wojskowości", 16, 2 (1970), S. 19-61.

Haug W., Das ,ritterliche Tugensystem“. Norm oder Herausforderung?, in: Symposium „Das Mittelalter in der Gegenwart", 25.-27.09.1995, hg. v. I. Hoppner, (Veröffentlichungen des Japanisch-Deutschen Zentrums Berlin. Reihe 1, Deutsch 30, 1996), S. 56-70.

Hellmann M., Die polnisch-litauische Union von 1385/1386. Betrachtungen zu ihrem 600jährigen Gedächtnis, „Jahrbücher für Geschichte Osteuropas N. F.“, 34 (1986), S. 19-34.

Hemmerle J., Die Deutschordens-Ballei Böhmen in ihren Rechnungsbüchern 1382-1411, (Quellen und Studien zur Geschichte des Deutschen Ordens 22, 1967). 
Hoensch J. K., König/Kaiser Sigismund, der Deutsche Orden und Polen-Litauen. Stationen einer problembeladenen Beziehung, „Zeitschrift für OstmitteleuropaForschung", 46, 1 (1997), S. 1-44.

Hofmann H. H., Der Staat des Deutschmeisters. Studien zu einer Geschichte des Deutschen Ordens im Heiligen Römischen Reich Deutscher Nation, (Studien zur bayerischen Verfassungs- und Sozialgeschichte 3, 1964).

Holbach R., „Disz ist dy ansprache dy wir dun wydder unssern heren... “. Bemerkungen zur Regierungszeit des Erzbischofs Otto von Ziegenhain (1418-1430), „Kurtrierisches Jahrbuch“, 23 (1983), S. 17-35.

Hubert N. Z., Międzynardowe procesy polubowne jako narzędzie polityki Zygmunta Luksemburskiego w pótnocnej i środkowowschodniej Europie (1412-1424),(1981). Israel O., Das Verhältnis des Hochmeisters des Deutschen Ordens zum Reich im 15. Jahrhundert, (Wissenschaftliche Beiträge zur Geschichte und Landeskunde OstMitteleuropas 4, 1952).

Iwańczak W., Czy Jan Luksemburski był wrogiem Polski?, „Mówią Wieki“, 40, 4-5 (1997), S. 17-21.

Iwańczak W., Jan Luksemburski a Polska, in: Polacy w Czechach, Czesi w Polsce X-XVIII wiek, hg. v. H. Gmiterka, W. Iwańczak, (2004), S. 13-30.

Iwańczak W., Krucjaty Jana Luksemburskiego, in: Rycerstwo Europy ŚrodkowoWschodniej wobec idei krucjat, hg. v. W. Peltz, J. Dudek, (Historia 5, 2002), S. 113-121.

Jähnig B., Der Deutsche Orden und Karl IV., in: ders., Vorträge und Forschungen zur Geschichte des Preußenlandes und des Deutschen Ordens im Mittelalter. Ausgewählte Beiträge zum 70. Geburtstag am 7. Oktober 2011, hg. v. H.-J. Kämpfert, B. Kämpfert, (Quellen und Darstellungen zur Geschichte Westpreußens 34, 2011), S. $16-66$.

Kahl H.-D., Die völkerrechtliche Lösung der „Heidenfrage“ bei Paulus Vladimiri von Krakau (+1435) und ihre problemgeschichtliche Einordnung, ,Zeitschrift für Ostforschung", 7 (1958), S. 161-209.

Kiaupienè J., 1385 m. rugpjūčio 14 d. Krèvos aktas, (2002).

Koczerska M., Autentyczność dokumentu unii krewskiej 1385 roku, „Kwartalnik Historyczny", 99, 1 (1992), S. 59-80.

Korczak L., O akcie krewskim raz jeszcze (na marginesie rozprawy Jonasa Dainauskasa), „Studia Historyczne“, 34, 3 (1991), S. 473-479.

Krzywiak L., ,Via concordiae“czy „via iustitiae“- jeszcze w sprawie „ostatniego słowa“ Pawła Włodkowica o Zakonie krzyżackim, in: Cracovia - Polonia - Europa. Studia $z$ dziejów średniowiecza ofiarowane Jerzemu Wyrozumskiemu w szęśćdziesiąta 
piąta rocznice urodzin i czterdziestolecie pracy naukowej, hg. v. W. Bukowski (et al.), (1995), S. 323-327.

Krzyżaniakowa J., Andrzej Łaskarz - „patron“ polskich koncyliarystów, in: Ludzie, kościót, wierzenia. Studia z dziejów kultury i społeczeństwa Europy Środkowej (średniowiecze - wczesna epoka nowożytna), hg. v. W. Iwańczak, (2001), S. 265-278.

Kuczyński S. M., Wielka wojna z Zakonem Krzyżackim w latach 1409-1411,(1987). Kwiatkowski S., Der Deutsche Orden im Streit um Polen-Litauen. Eine theologische Kontroverse über den Krieg und Frieden auf dem Konzil von Konstanz (1414-1418), (2000).

Libor J.,Zkáza českomoravské bailie řádu německých rytírů „Časopis Matice moravské“, 117 (1998), S. 383-391.

Łowmiański H., Akt krewski z 14 sierpnia 1385 roku, „Nurt“, 21, 8 (1985), S. 22-24.

Lübke C., Das östliche Europa, (Die Deutsche und das europäische Mittelalter, 2004).

Lückerath C. A., Melnosee, Friede von (1422), in: Lexikon des Mittelalters, 6 (1993), Sp. 502.

Małłek J., Königliches Preußen, Ordensstaat und Herzogtum Preußen im 15. und 16. Jahrhundert. Entfremdung oder wirtschaftliche und politische Annäherung, ,Blätter für deutsche Landesgeschichte", 115 (1979), S. 1-14.

Matijov J., Der polnisch-ungarische Streit um Galizien und Lodomerien (Ein Beitrag zur österreichischen Geschichte), (1886).

Mentzel-Reuters A., Arma spiritualia. Bibliotheken, Bücher und Bildung im Deutschen Orden, (Beiträge zum Buch- und Bibliothekswesen 47, 2003), S. 340-343.

Miethke J., Die Polen auf dem Konstanzer Konzil. Der Konflikt um den Dominikaner Johannes Falkenberg, in: Das Konstanzer Konzil 1414-1418. Weltereignis des Mittelalters. Essays, hg. V. K.-H. Braun (et al.), (2013), S. 106-110.

Miethke J., Heiliger Krieg? Theoretische Kontroversen zwischen Deutschem Orden und dem Königreich Polen vor und auf dem Konstanzer Konzil, in: Heilige Kriege. Religiöse Begründungen militärischer Gewaltanwendung. Judentum, Christentum und Islam im Vergleich, hg. v. K. Schreiner, E. Müller-Luckner, (2008), S. 109-125. Militzer K., Auswirkungen der Schlacht bei Tannenberg auf den Deutschen Orden, in: Žalgirio laikų Lietuva ir jos kaimynai, hg. v. R. Čapaite, A. Nikžentaitis, (Acta Historica Universitatis Klaipedensis 1, 1993), S. 94-112.

Mironowicz A., Kościót prawosławny w państwie Piastów i Jagiellonów, (2003).

Neitmann K., Die ostpreußischen Stände und die Außenpolitik des Deutschen Ordens vom I. Thorner Frieden bis zum Abfall des Preußischen Bundes (1411-1454), in: Ordensherrschaft, Stände und Stadtpolitik. Zur Entwicklung des Preußenlandes im 
14. und 15. Jahrhundert, hg.v. U. Arnold, (Schriftenreihe Nordost-Archiv 25, 1985), S. 27-71.

Neitmann K., Zur Revindikationspolitik des Deutschen Ordens nach Tannenberg. Die Auseinandersetzung zwischen $d$. Deutschen Orden und Polen-Litauen um die Ratifizierung des Friedensvertrages vom Melno-See 1422/1423, „Jahrbücher für Geschichte Osteuropas N. F.", 31,1 (1983), S. 50-80.

Nikodem J., Wróg Królestwa Polskiego. Zygmunt Luksemburski w opinii Jana Długosza, in: Cor hominis. Wielkie namiętności $w$ dziejach, źródłach i studiach nad przeszłością, hg. v. S. Rosik, P. Wiszewski, (Acta Universitatis Wratislaviensis. Historia 176, 2007), S. 183-199.

Nowak B., Krewo - Lublin - Kraków 1385-1386. W kregu twórców unii polsko-litewskiej, in: Unia Lubelska 1569 roku w dziejach Polski i Europy, hg. v. A. A. Witusik, (2004), S. 7-12.

Nowak Z. H., Bemerkungen zur frühen Geschichte der Stände in Preußen, in: Die Anfänge der ständischen Vertretungen in Preußen und seinen Nachbarländern, hg. v. H. Boockmann, E. Müller-Luckner (Schriften des Historischen Kollegs. Kolloquien 16, 1992), S. 52-54.

Nowak Z. H., Protokół z rokowań polsko-krzyżackich w Grabiu i na kępie wiślanej pod Raciążkiem w roku 1414,„Ordines militares“, 2 (1984), S. 147-175.

Paszkiewicz B., Jak Zygmunt Luksemburski nie został królem Polski. Kilka uwag o domniemanym skarbie z Hrabušic, in: Lucemburkové. Mince, medaile, hg. v. D. Grossmannová, J. Hásková, J. T. Štefan, (Penize v proměnách času 5, 2006), S. 23-34.

Persch M., Otto von Ziegenhain, in: Biographisch-Bibliographisches Kirchenlexikon, 6 (1993), S. 1375-1377.

Polejowski K., The Teutonic Order's Propaganda in France during the Wars against Poland and Lithuania (Fifteenth Century), in: Die geistlichen Ritterorden in Mitteleuropa. Mittelalter, hg. v. K. Borchardt, J. Libor, (Edice Země a kultura ve střední Evropě 20, 2011), S. 233-244.

Press V., „Des deutschen Adels Spital“. Der Deutsche Orden zwischen Kaiser und Reich, in: Der Deutsche Orden in Tirol. Die Ballei an der Etsch und im Gebirge, hg. v. H. Noflatscher, (Quellen und Studien zur Geschichte des Deutschen Ordens 43, 1991), S. 1-42.

Reid C. J., Paulus Vladimiri, the Tractatus Opinio Hostiensis and the Rights of Infidels, in: Sacri canones servandi sunt. Ius canonicum et status ecclesiae saeculis XIII-XV, (Opera Instituti Historici Pragae. Series C, Miscellanea 19, 2008), S. 418-423.

Russell F. H., Paulus Vladimiri's Attack on the Just War. A Case Study in Legal Polemics, in: Authority and Power. Studies on Medieval Law and Government Presented to 
Walter Ullmann on his Seventieth Birthday, hg. v. B. Tierney, P. A. Linehan, (1980), S. 237-254.

Salmonowicz S., Königliches Preußen und polnisch-litauischer Staat (1466-1772), in: Reiche und Territorien in Ostmitteleuropa. Historische Beziehungen und politische Herrschaftslegitimation, hg. v. D. Willoweit, H. Lemberg, (Völker, Staaten und Kulturen in Ostmitteleuropa 2, 2006), S. 81-91.

Sarnowsky J., Der Deutsche Orden, (Beck'sche Reihe 2428, 2007)

Sarnowsky J., Die Wirtschaftsführung des Deutschen Ordens in Preußen (1382-1454), (Veröffentlichungen aus den Archiven Preußischer Kulturbesitz 34, 1993).

Seiler J., Der Deutsche Orden in Frankfurt. Gestalt und Funktion einer geistlich-ritterlichen Institution in ihrem reichsöffentlichen Umfeld, (Quellen und Studien zur Geschichte des Deutschen Ordens 61,2003).

Sieradzan W., Der Thorner Frieden von 1411 und die Prozesse zwischen dem Deutschen Orden und Polen als Beispiel der Bewältigung zwischenstaatlicher Konflikte im Spätmittelalter, in: Konfliktbewältigung und Friedensstiftung im Mittelalter, hg. v. R. Czaja, E. Mühle, A. Radzimiński, (2012), S. 135-150.

Sikora F., Kilka uwag o konflikcie wegiersko-polskim w roku 1410, ,Rocznik NaukowoDydaktyczny WSP w Krakowie. Prace Historyczne“, 12 (1987), S. 105-118.

Skrzypek J., Zygmunt Luksemburski i jego polityka wobec Polski w latach 1386-1399, „Sprawozdania Towarzystwa Naukowego we Lwowie“, 12, 3 (1932), S. 183-190. Springmann K., Polen und der Deutsche Orden zur Zeit des Konstanzer Konzils, (1923).

Srodecki P., „Murus et antemurale pollens et propugnaculum tocius christianitatis." Der Traktatenstreit zwischen dem Deutschen Orden und dem Königreich Polen auf dem Konstanzer Konzil, „Schweizerische Zeitschrift für Religions- und Kulturgeschichte", 109 (2015), S. 47-65.

Srodecki P., Antemurale Christianitatis. Zur Genese der Bollwerksrhetorik im östlichen Mitteleuropa an der Schwelle vom Mittelalter zur Frühen Neuzeit, (2015).

Srodecki P., Contre les ennemis de la foy de Dieu. Der Kreuzzug von Nikopolis und das abendländische Türkenbild um 1400, in: Das Bild des Feindes. Konstruktion von Antagonismen und Kulturtransfer im Zeitalter der Türkenkriege, hg. v. E. Leuschner, T. Wünsch, (2013), S. 33-49.

Srodecki P., Schilt der Cristenheite i Scutum christianitatis - spory polsko-krzyżackie a retoryka przedmurza/tarczy na początku XV wieku, in: Unia w Horodle na tle stosunków polsko-litewskich. Od Krewa do Zaręczenia wzajemnego Obojga Narodów, hg. v. S. Górzyński, (2015), S. 147-163.

Sroka S. A., Ścibor ze Ściborzyc. Rys biograficzny, in: Polska i jej sąsiedzi w późnym 
średniowieczu. Profesorowi Jerzemu Wyrozumskiemu - uczniowie, hg. v. K. Ożóg, S. Szczur, (2000), S. 139-158.

Szweda A., Organizacja $i$ technika dyplomacji polskiej $w$ stosunkach $z$ zakonem krzyżackim w latach 1386-1454, (2009).

Tannenberg - Grunwald - Žalgiris 1410. Krieg und Frieden im späten Mittelalter, hg. v. W. Paravicini (et al.), (2012).

Tęgowski J., Bezkrólewie po śmierci Ludwika Wegierskiego a geneza unii Polski z Litwa, in: Studia historyczne z XIII-XV wieku. Wydanie jubileuszowe z okazji 75-lecia urodzin i 45-lecia pracy naukowej Profesora doktora Kazimierza Jasińskiego, hg. v. J. Śliwiński, (Studia i materiały WSP w Olsztynie 86, 1995), S. 87-110.

Vetter H., Die Beziehungen Wenzels zum Deutschen Orden von 1384-1411,(1912). W 600-lecie aktu krewskiego, hg. v. M. Biskup, „Zapiski Historyczne“, 51 (1986).

Weise E., Entwicklungsstufen der Verfassungsgeschichte des Ordensstaats Preußen im 15. Jahrhundert, „Zeitschrift für Ostforschung“, 7 (1958), S. 1-17.

Wiesiołowski J., Prace i projekty Pawła Włodkowica. Konstancja, zima 1415 i 1416 roku, ,Roczniki Historyczne“, 35 (1969), S. 93-123.

Wisner H., Spory o Krewo, „Zapiski Historyczne“, 69, 2-3 (2004), S. 169-179.

Włodek Z., La Satire de Jean Falkenberg. Texte inédit avex introduction, (1973).

Wojna Polski i Litwy z zakonem krzyżackim w latach 1409-1411, hg. v. S. Jóźwiak (u. a.), (2010). 